\title{
SNX27, a Protein Involved in Down Syndrome, Regulates GPR17 Trafficking and Oligodendrocyte Differentiation.
}

Veronica Meraviglia $^{1 *}$, Alessandro Francesco Ulivi ${ }^{1 *}$, Marta Boccazzi ${ }^{2}$, Fabiola Valenza ${ }^{1}$, Alessandra

Fratangeli $^{1}$, Maria Passafaro ${ }^{1}$, Davide Lecca $^{2}$, Fiorenza Stagni ${ }^{3}$, Andrea Giacomini ${ }^{3}$, Renata Bartesaghi $^{3}$, Maria P. Abbracchio ${ }^{2}$, Stefania Ceruti $^{2}$ and Patrizia Rosa\# ${ }^{1}$

${ }^{1}$ CNR - Institute of Neuroscience, Department of Medical Biotechnologies and Translational Medicine (BIOMETRA), Università degli Studi di Milano, Milan, Italy; ${ }^{2}$ Laboratory of Molecular and Cellular Pharmacology of Purinergic Transmission, Department of Pharmacological and Biomolecular Sciences (DiSFeB), Università degli Studi di Milano, Milan, Italy; ${ }^{3}$ Department of Biomedical and Neuromotor Sciences, Università degli Studi di Bologna, Bologna, Italy.

*These authors contributed equally to the study.

Running title: Role of SNX27 in oligodendrocyte differentiation.

Total word count: 14,857

Number of words in:

Abstract: 249

Introduction: 1,039

Materials and methods: 2,797

Results: 3,574

Discussion: 2,153

Acknowledgements: 139

Bibliography: 2,662

Figure legends: 2,023

Number of tables: 2

Number of figures: 11

Number of Supporting Information Figures: 8

\#To whom correspondence should be addressed: Patrizia Rosa, CNR Institute of Neuroscience Via Vanvitelli 32, 20129 Milano MI, Italy. Tel: +39-0250316974; Fax: +39-0250317132 E-mail: p.rosa@in.cnr.it

\section{Main Points:}

- SNX27 modulates membrane recycling of GPR17

- In maturing oligodendrocytes (OLs) SNX27 down-regulation triggers degradation of GPR17 and 
accelerates myelination

- SNX27, GPR17 expression and OL maturation are altered in a model of Down syndrome 


\section{ABSTRACT}

The G protein-coupled receptor 17 (GPR17) plays crucial roles in myelination. It is highly expressed during transition of oligodendrocyte progenitor cells to immature oligodendrocytes, but, after this stage, it must be down-regulated to allow generation of mature myelinating cells. After endocytosis, GPR17 is sorted into lysosomes for degradation or recycled to the plasma membrane. Balance between degradation and recycling is important for modulation of receptor levels at the cell surface and thus for the silencing/activation of GPR17-signaling pathways that, in turn, affect oligodendrocyte differentiation. The molecular mechanisms at the basis of these processes are still partially unknown and their characterization will allow a better understanding of myelination and provide cues to interpret the consequences of GPR17 dysfunction in diseases. Here, we demonstrate that the endocytic trafficking of GPR17 is mediated by the interaction of a type I PDZ-binding motif located at the C-terminus of the receptor and SNX27, a recently identified protein of the endosome-associated retromer complex and whose functions in oligodendrocytes have never been studied. SNX27 knock-down significantly reduces GPR17 plasma membrane recycling in differentiating oligodendrocytes while accelerating cells' terminal maturation. Interestingly, trisomy-linked down-regulation of SNX27 expression in the brain of Ts65Dn mice, a model of Down syndrome, correlates with a decrease in GPR $17^{+}$cells and an increase in mature oligodendrocytes, which, however, fail in reaching full maturation, eventually leading to hypomyelination. Our data demonstrate that SNX27 modulates GPR17 plasma membrane recycling and stability, and that disruption of the SNX27/GPR17 interaction might contribute to pathological oligodendrocyte differentiation defects.

Key words: Receptor endocytosis, myelination, PDZ-binding motif, PDZ-domain. 


\section{INTRODUCTION}

Oligodendrocytes (OLs) are the myelinating cells of the central nervous system (CNS). They have attracted growing interest based on evidence showing that myelination defects are observed in many brain disorders, from "classical" demyelinating diseases, such as multiple sclerosis, to stroke, schizophrenia, depression, Down syndrome and autism, among others (Fields, 2008). The OL developmental program begins with specification of oligodendrocyte progenitor cells (OPCs) during late embryonic gestation. Postnatally, OPCs differentiate through pre-myelinating stages to become mature OLs with many branched processes that wrap around axons and form membrane sheaths of myelin. In the adult brain, OPCs are still present, scattered throughout the brain parenchyma, and continue to differentiate into mature myelinating OLs.

OL differentiation is regulated by a complex interplay of intrinsic, epigenetic and extrinsic factors (Mitew et al., 2014 and refs therein), including the G protein-coupled receptor (GPCR) referred to as GPR17, which is located at an intermediate phylogenetic position between purinergic P2Y and cysteinylleukotriene receptors. Both recombinant and native GPR17 receptors respond to both extracellular nucleotides (UDP, UDP-glucose) and cysteinyl-leukotrienes (Ciana et al., 2006). GPR17 is highly expressed during the transition from OPCs to immature OLs, but after this stage, it must be downregulated to permit the generation of mature fully myelinating cells (Lecca et al. 2008; Chen et al., 2009; Boda et al., 2011; Ceruti et al., 2011; Fumagalli et al., 2011; 2015). In agreement with this finding, GPR17 activation/inactivation by natural or synthetic agonists/antagonists has different effects on OPC differentiation and myelination (Lecca et al., 2008; Fumagalli et al., 2011; Dougherty et al., 2012; Mao et al., 2012; Coppi et al., 2013; Hennen et al., 2013). While forced overexpression of GPR17 during late stages of differentiation leads to defective myelination in vitro and in vivo, GPR17 knock-out in mice determines an early onset of OL myelination (Chen et al., 2009). Characterization of the mechanisms controlling the expression of GPR17 at the plasma membrane may therefore contribute to a better understanding of the molecular mechanisms underlying its role in OL maturation and provide a context in which to interpret its dysfunction in disease states. Following agonist activation, GPR17 undergoes $\beta$-arrestin/clathrin-mediated internalization in early endosomes, and is subsequently sorted to lysosomes for degradation or to recycling endosomes for re-incorporation into the plasma membrane (Fratangeli et al., 2013, Hennen et al., 2013; Daniele et al., 2014). The balance between degradation and recycling regulates the number of receptors at the cell surface, with important implications in the silencing or activation of GPR17- signaling pathways and, possibly, in OL differentiation. To shed light on the mechanisms underlying GPR17 trafficking and sorting into the endocytic pathways, we analyzed the role of a putative type I PSD95, Disc-large, Zo-1 (PDZ)-binding motif (Niethammer et al., 1996; Lee et al., 1997; Songyang et al., 1997) present at the C-terminal region of the receptor, whose function was completely unknown, and searched for possible binding proteins. Among the potential interactors, we focused our attention on two PDZ domain-containing proteins, the $\mathrm{Na}(+) / \mathrm{H}(+)$ exchanger regulatory factors (NHERFs) and the phox-homology (PX) domain-containing sorting nexin 27 (SNX27) proteins for the following reasons: i) they interact with many GPCRs; ii) they are expressed in various tissues, including the brain, and iii) the mechanisms underlying their functions in modulating receptor internalization/signaling or recycling are well documented. NHERF1 and 2 are widely expressed scaffold proteins that have been reported to affect, via different mechanisms, the trafficking and signaling of a 
number of GPCRs (Ardura and Friedman, 2011), including the purinergic receptors P2Y1 and P2Y12 (Fam et al., 2005; Nisar et al., 2012), which share similarities with GPR17 (Ciana et al. 2006). SNX27 is a member of a large family of endosomal trafficking proteins that differs from the other members of the same family because it contains a PDZ domain (Carlton et al., 2005). SNX27 is targeted to early endosomal membranes by the PX domain (Cai et al., 2011) and has originally been shown to play a crucial role in the trafficking of a 5- hydroxytryptamine receptor 4 variant containing a type I PDZbinding motif (Joubert et al., 2004). Moreover, recent data demonstrate that SNX27 is required for the recycling to the plasma membrane of a number of receptors and ion channels, including glutamate receptors, AMPA and NMDA, and GIRK (G protein-coupled inwardly-rectifying potassium) channels, by linking them to "retromer complexes" that mediate trafficking of proteins from endosomes to the cell surface (Lunn et al., 2007; Lauffer et al., 2010; Balana et al., 2011; Temkin et al., 2011; Steinberg et al., 2013; Loo et al., 2014). Loss of SNX27 enhances the degradation of the target proteins, thus confirming its role in diverting proteins from lysosomes to plasma membrane (Lauffer et al., 2010). SNX27 is essential for mouse development because SNX $27^{+/}$knock-out mice die at one month of age (Cai et al., 2011). On the other hand, SNX27 $7^{+-}$mice show several defects including a cognitive impairment that mimics cognitive defects characterizing human Down syndrome (DS), for which a significant reduction of SNX27 expression has been reported (Wang et al., 2013 and 2014). On the basis of these studies it can be expected that SNX27 plays an important role in the physiology and survival of many different cell types.

Based on these data and on the observation that GPR17 contains a putative type I PDZ binding motif, in this study we analyzed the role of SNX27 and NHERF1 in controlling GPR17 recycling in OLs. Our results demonstrate that SNX27, but not NHERF1, interacts with GPR17 and that it is crucial in controlling GPR17 plasma membrane recycling and expression in differentiating OL cells. Downregulation of SNX27 accelerates the degradation of GPR17 and, in turn, the differentiation of OPCs towards a more mature phenotype. In addition, we show a reduced number of GPR $17^{+}$immature OLs in the brains of Ts65Dn mice (a well characterized model of DS), which are known to express reduced levels of SNX27 (Wang et al., 2013), and demonstrate that this correlates with an increased number of mature $\mathrm{CC}^{+} \mathrm{OLs}$, which show, however, a lower expression of myelin proteins, thus suggesting an impaired terminal maturation of OLs. Taken together, our data support a relevant role for SNX27 in OL differentiation through the interaction with GPR17, which may have potential implications for OL differentiation defects in pathological settings. 


\section{MATERIALS AND METHODS}

\section{Materials and antibodies}

The list of primary antibodies utilized in the study is reported in Table 1. UDP-glucose, protease inhibitor cocktail, dithiothreitol (DTT), anti-rabbit and mouse IgG conjugated to horseradish peroxidase, anti-rabbit IgG-light chain conjugated to horseradish peroxidase, and biotinylated anti-goat IgG were obtained from Sigma-Aldrich (Milan, Italy). IR Dye $800 \mathrm{CW}$ goat anti-rabbit IgG and IR Dye 680 RD goat anti-mouse IgG were from Li-Cor Biosciences (Cornaredo, Milan, Italy). Anti-rat IgG conjugated to horseradish peroxidase, goat anti-rabbit IgG or goat anti- mouse IgG conjugated to AlexaFluor® 488 and Streptavidin conjugated to AlexaFluor ${ }^{\circledR} 555$ were purchased from Life Technologies (Monza, Italy). Antibodies against the C-terminal region of GPR17 ( $\langle\mathrm{Ct}-\mathrm{GPR} 17)$ and the N-terminal region of mouse GPR17 ( $(\mathrm{Nt}-\mathrm{GPR} 17)$ were raised in rabbits, affinity-purified, and characterized as previously described (Fratangeli et al., 2013; Table 1). To follow GPR17 internalization in rat primary OPCs, a new antibody (from here on referred to as $\langle$ Nt-rGPR17) was raised in rabbits using a synthetic peptide corresponding to the N-terminal sequence of rat GPR17 (MDG-LETALPSLTDNASLAYSEQC) coupled to keyholelimpet hemocyanin, and affinity-purified. Its specificity for rat GPR17 was demonstrated by Western blotting and immunofluorescence on rat primary OPC cultures after preadsorption with the antigen (data not shown). The DyLight488-, FITC-, Cy3-, Cy2- and Cy5-conjugated anti-mouse, rabbit or rat IgGs were purchased from Jackson ImmunoResearch Laboratories (West Grove, PA, USA). AlexaFluor 488-conjugated streptavidin was from Termo-Fisher Scientific (Waltham, MA, USA). The transfection reagents TurboFECT and JetPei were obtained from Thermo Scientific and Polyplus Transfection (Illkirch, France), respectively. HisPur ${ }^{\mathrm{TM}}$ Ni-NTA Resin was purchased from Thermo Scientific.

\section{Plasmids and site-directed mutagenesis}

The pCMVEntry-human(h)SNX27 conjugated to Myc and FLAG epitopes was purchased from OriGene Technologies (Rockville, MD 20850), and it was then sub-cloned into pcDNA3 without the FLAG epitope (SNX27 wild-type). The hSNX27 conjugated to histidine (His-SNX27) was obtained by sub-cloning hSNX27 into the pRSETB vector (Life Technologies). The pcDNA3.1/V5-His-TOPO mGPR17 was obtained as previously described (Lecca et al., 2008). The pFLAG-CMV2-hGPR17 was obtained by subcloning in frame with the upstream FLAG sequence the human GPR17 receptor from a previously generated pcDNA3.1 vector (Life Technologies) into a pFLAG-CMV2 expression vector (Sigma-Aldrich). The appropriate control RNA (CSHCTR001- CU6) and short hairpin (sh)-RNAs cloned into a psi-U6.1 vector carrying EGFP-cDNA and targeting the SNX27 sequences 1) catgaggctgataacctag, 2) ggccattctcattatcaga, 3) ctggcacctaatgaatttc and 4) actctacgtccagaactat were purchased from GeneCopoeia (Rockville, MD). The pcDNA3 vector was from Life Technologies. The GPR17 cDNA in pcDNA3.1/V5-His-TOPO and in pFLAG-CMV2 plasmids and the SNX27 cDNA in pRSET B plasmid were mutagenized using the QuickChange Lighting Site-Directed Mutagenesis Kit (Agilent Technologies, La Jolla, CA, USA). The mutations (Table 2) were introduced by PCR using a Pfu-based polymerase followed by digestion with DpnI enzyme to remove the parental DNA. The specific primers designed to obtain the mutants used herein were as follows:

Stop F (5'-CTCCCTGAGTGCCTGATCCGAGCTGTG-3'); 
Stop R (5'-CACAGCTCGGATCAGGCACTCAGGGAG-3');

RAAL F (5'-CCCTGAGTGCCCGAGCCGCGCTGTGAGAAGG-3');

RAAL R (5'CCTTCTCACAGCGCGGCTCGGGCACTCA-GGG-3');

RAEL F (5'-CCCTGAGTGCCCGAGCCGAGCTGTG-3');

RAEL R (5'-CACAGCTCGGCTCGGGCACTCAGGG-3');

RSELA F (5'-GTGCCCGATCCGAGCTGGCATAAGGGCAATTCTGCAGA-3');

RSELA R (5'-TCTGCAGAATTGCCCTTATGCCAGCTCGGATCGGGCAC-3');

KSELA F (5'-GCCAAGTCAGAGCTGGCATGATCTAGAGGATCCC-3');

KSELA R (5'-GGGATCCTCTAGATCATGCCAGCTCTGACTTGGC-3');

KAEL F (5'-GCTCGCTGAGTGCCAAGGCAGAGCTGTGATCTAGAGG-3');

KAEL R (5'-CCTCTAGATCACAGCTCTGCCTTGGCACTCAGCGAGC-3').

SNX27 H114A F (5'-GAATGTTGAGGGGGCGACAGCCAAGCAGGTGGTGGACC-3');

SNX27 H114A R (5'-GGTCCACCACCTGCTTGGCTGTCGCCCCCTCAACATTC-3').

All construct sequences were verified by Eurofins MWG Operon (Ebersberg, Germany).

\section{Cell cultures}

The murine Oli-neu OPC line (kindly provided by Professor J. Trotter, University of Mainz, Germany) was maintained in Sato medium containing 1\% horse serum (HS; Jung et al., 1995; Winterstein et al., 2008) at $37^{\circ} \mathrm{C}$ and $10 \% \mathrm{CO}_{2}$. Differentiation into immature OLs and then into mature OLs was performed by incubating the cells in Sato plus conditioned medium (CM; 1:1 ratio) obtained from neuron primary cultures (Fratangeli et al., 2013). The HEK293 cell line was grown in DMEM containing 10\% fetal bovine serum, $1 \%$ penicillin/streptomycin and $2 \mathrm{mM} \mathrm{L}$-glutamine, at $37^{\circ} \mathrm{C}$ and $10 \% \mathrm{CO} 2$. Enriched OPC primary cultures were prepared from mixed glial cultures of cortices from postnatal day 3 (P3) C57BL/6 mice or P2 Sprague-Dawley rats using a selective detachment procedure described previously (Fumagalli et al., 2011; Medina-Rodriguez et al., 2013). OPCs were then seeded onto petri dishes or coverslips coated with poly-L-lysine and grown in Sato medium without tyroxine supplemented with 10 $\mathrm{ng} / \mathrm{mL}$ bFGF and $10 \mathrm{ng} / \mathrm{mL}$ PDGF-AA. After two days, the cells were transfected as described below and then incubated in complete Sato medium without growth factors to allow differentiation.

Plasmid transfections

The day before transfection, Oli-neu or HEK293 cells were seeded onto $24 \times 24 \mathrm{~mm}$ glass coverslips (75,000 Oli-neu or 150,000 HEK293/coverslip), $60 \mathrm{~mm}$ Petri dishes (180,000 Oli- neu/Petri dish) or $100 \mathrm{~mm}$ Petri dishes (1,500,000 HEK293 cells/Petri dish) for $24 \mathrm{~h}$, and then transfected with the appropriate vectors using JetPei (PolyPlus) or TurboFECT (Thermo Scientific). The 24x24 mm coverslips were transfected with 0.5 (g (Oli-neu) or 1 (g of DNA (HEK293), the $60 \mathrm{~mm}$ Petri dishes were transfected with 1 g g of DNA, and the $100 \mathrm{~mm}$ Petri dishes were transfected with 2.5 (Oli-neu) or 5 (g of DNA (HEK293). In the co-transfection experiments, the vectors were mixed in a 1:1 ratio. After 48 or $72 \mathrm{~h}$, cells were fixed in paraformaldehyde or lysed (see below). For SNX27 silencing, Oli-neu cells or OPCs were seeded onto $24 \mathrm{~mm}$ and $16 \mathrm{~mm}$ diameter glass coverslips, respectively (ranging from 30,000 to 75,000 cells/coverslip) or $60 \mathrm{~mm}$ Petri dishes (ranging from 165,000 to 180,000 cells/Petri dish) on the day before transfection. After $24 \mathrm{~h}$ or $48 \mathrm{~h}$, respectively, Oli-neu cells and OPCs were 
transfected with shRNAs ( 0.5 to $1 \mu \mathrm{g}$ of plasmid for sample) using JetPei or TurboFECT, and after $24 \mathrm{~h}$ the medium was replaced with fresh Sato medium without (OPCs) or with CM (Oli-neu). Seventy-two hours after transfection, cells were fixed or lysed as described below.

\section{Cell lysis, nuclei/cytosol fractionation and pull-down experiments}

Cells were incubated for $30 \mathrm{~min}$ on ice in buffer A $(150 \mathrm{mM} \mathrm{NaCl}, 2 \mathrm{mM}$ EGTA, $50 \mathrm{mM}$ Tris$\mathrm{HCl}, \mathrm{pH} 7.5$, containing $1 \%$ Triton $\mathrm{X}-100$ and protease inhibitors). For the pull-down experiments, Olineu cells were solubilized in buffer B (PBS, pH 7.4, 2.5 mM EDTA and 10\% glycerol containing 0.5\% Nonidet P40 and protease inhibitors). The lysates were then centrifuged at $12,000 \mathrm{rpm}$ for $30 \mathrm{~min}$ at $4{ }^{\circ} \mathrm{C}$. For the incubations with His-Pur-Ni-NTA resin, EGTA was removed from the buffer. For the fractionation of nuclei and cytosol, cells were collected using buffer $\mathrm{C}$ (10 mM Hepes, $10 \mathrm{mM} \mathrm{KCl,} 1.5$ $\mathrm{mM} \mathrm{MgCl}$ 2, $0.5 \mathrm{mM}$ DTT, $\mathrm{pH} 7.9$, containing protease inhibitors) and mechanically lysed using $2.5 \mathrm{ml}$ syringes and 18Gx1.5' needles (Terumo, Leuven, Belgium). Cytosolic fraction was separated by centrifuging samples at 1,200 rpm for $10 \mathrm{~min}$ at $4^{\circ} \mathrm{C}$. The nuclear fraction was resuspended in buffer D (400 mM NaCl, $20 \mathrm{mM}$ Hepes, 25\% glycerol, $0.2 \mathrm{mM}$ EDTA), incubated on ice for $40 \mathrm{~min}$, and centrifuged at $40,000 \mathrm{rpm}$ and $4^{\circ} \mathrm{C}$ for $40 \mathrm{~min}$. When needed, proteins were precipitated by overnight incubation in $100 \%$ acetone at $-20^{\circ} \mathrm{C}$ followed by centrifugation for $30 \mathrm{~min}$ at $10,000 \mathrm{rpm}$ and $4^{\circ} \mathrm{C}$. For His-SNX27 purification, BL21DE3 E. coli bacteria were transformed with pRSETB-His-SNX27 vectors. The bacterial pellets were resuspended in $20 \mathrm{mM}$ phosphate buffer and lysed by cycles of freezing in liquid nitrogen and thawing at $42^{\circ} \mathrm{C}$. His-SNX27 was purified from a $200 \mathrm{~mL}$ culture of bacteria using 200 (L of nickel-nitrilotriacetic acid resin (Thermo Scientific) according to the manufacturer's instructions. Imidazole was removed from the eluted samples by filtering in an Amicon Ultra Centrifugal Filter (Millipore). GPR17 C-terminal peptide (CT) or a GPR17 C-terminal peptide lacking the PDZ- binding motif ( $\triangle \mathrm{CT}$ ) was coupled to $\mathrm{CNBr}$-activated sepharose $4 \mathrm{~B}$ at a concentration of 2 $\mathrm{mg} / \mathrm{mL}$ of matrix. Aliquots of Oli-neu lysates (500 ( $\mathrm{g}$ of total proteins), BL21DE3 bacterial extracts (50 $(\mathrm{L})$ or purified His-SNX27 (2 (g), all adjusted in buffer B containing $0.2 \%$ Nonidet P40 with protease inhibitors, were then incubated overnight at $4^{\circ} \mathrm{C}$ with 25 or $10 / \mathrm{L}$ of the resins. Samples were washed three times in buffer B containing $0.2 \%$ Nonidet P40 and three times in buffer B without detergent. The proteins bound to the resin-conjugated peptides were then solubilized in Laemmli's sample buffer and analyzed by gel electrophoresis and Western blotting.

\section{Western blot analysis}

Proteins were separated in $8 \%$ or $12 \%$ acrylamide/bisacrylamide gels and then transferred to a 0.45 (m PVDF membrane (Amersham Hybond-P; GE Healthcare, Little Chalfont, UK) or a $0.45 \curlyvee \mathrm{m}$ nitrocellulose membrane (Whatman, Dossel, Germany). The primary and secondary antibodies were incubated in tris-buffered saline (TBS, $50 \mathrm{mM}$ Tris- $\mathrm{HCl}, \mathrm{pH} 7.5,150 \mathrm{mM} \mathrm{NaCl}$ ) containing $5 \%$ non-fat milk and $0.3 \%$ Tween 20 for $2 \mathrm{~h}$ or $1 \mathrm{~h}$, respectively. For the anti-SNX27, anti-ID2 and anti-GAPDH antibodies, TBS containing 5\% non-fat milk and $0.1 \%$ Tween 20 were used. For anti- MBP antibody TBS+5\% non-fat milk and $0.05 \%$ Tween 20 was used and incubation was done overnight at $4^{\circ} \mathrm{C}$. The same protocol of incubation was utilized for anti-GRK2, anti-mTOR, and anti-phospho-mTOR, but in TBS+5\% non-fat milk. Anti-rabbit IgG, anti-mouse IgG (diluted 
1:50,000; in the case of anti-SNX27, diluted 1:25,000) or anti-rat IgG (diluted 1:5,000) conjugated to peroxidase were used as secondary antibodies. The peroxidase activity was revealed using a chemiluminescent substrate from Thermo Scientific. Alternatively, for quantitative analysis, the primary antibodies were detected using anti-rabbit IgG conjugated to IR Dye $800 \mathrm{CW}$ or anti-mouse IgG conjugated to IR Dye $680 \mathrm{RD}$ (diluted 1:10,000). The intensity of the secondary antibodies was detected and quantified using a Li-Cor Bioscience Odyssey CLx infrared imaging system.

\section{Antibody labeling of cell surface-exposed GPR17 in living cells}

Labeling of living cells was essentially performed as previously described (Fratangeli et al., 2013). Cells cultured on coverslips as described above were chilled to $4^{\circ} \mathrm{C}$, washed once in ice-cold PBS containing $0.1 \mathrm{mM} \mathrm{CaCl} 2,1 \mathrm{mM} \mathrm{MgCl}$ and $1 \% \mathrm{HS}$ (Oli-neu cells) or 1\% BSA (HEK293 cells), and then incubated at $4^{\circ} \mathrm{C}$ for 30 min with rabbit $\langle$ Nt-GPR17 or anti-FLAG antibodies (Table 1). Cells were washed five times and then either fixed with paraformaldehyde or incubated in Sato medium (Oli-neu cells) or DMEM (HEK cells) with or without 100 (M UDP-glucose. After 15 or 30 min of incubation at $37^{\circ} \mathrm{C}$, cells were chilled to $4^{\circ} \mathrm{C}$ to block endocytosis, washed with PBS (or when required with $50 \mathrm{mM}$ glycine buffer, $\mathrm{pH} 2.8$ ), re-incubated in Sato medium or DMEM without agonist at $37^{\circ} \mathrm{C}$ for 10 or 20 $\mathrm{min}$, and then processed for immunofluorescence.

\section{Immunofluorescence}

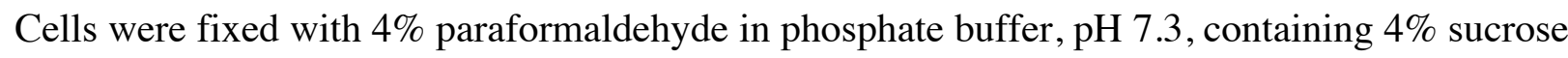
(8-10 min for Oli-neu, 15-20 min for HEK293 cells) and immunolabeled as previously described (Linetti et al., 2010). When required, they were permeabilized for 5-10 $\mathrm{min}$ at room temperature in PBS containing $0.1 \%$ or $0.3 \%$ Triton $\mathrm{X}-100$. The aldehyde complexes were neutralized by glycine washing, and, when required, endogenous avidin and biotin were neutralized using avidin/biotin blocking kit (Vector Laboratories, Burlingame, California). The primary and secondary antibodies and AlexaFluor 488-conjugated streptavidin were diluted in $10 \mathrm{mM}$ phosphate buffer and $450 \mathrm{mM} \mathrm{NaCl}$ containing $0.2 \%$ gelatin. For the co-staining of rabbit anti-NHERF1 (Thermo Scientific, Rockford, Illinois) and rabbit anti-Olig2 (Merck Millipore, Billerica, Maryland) the Tyramide Signal Amplification kit (Thermo-Fisher Scientific, Waltham, Maryland) was used according to manufacturer's instructions. The coverslips were mounted on slides with Mowiol 4-88 (PolyScience Europe, Eppelheim, Germany).

\section{Mouse Colony}

Female Ts65Dn mice carrying a partial trisomy of chromosome 16 (Reeves et al., 1995) were obtained from Jackson Laboratories (Bar Harbour, ME, USA) and maintained on the original genetic background by mating them with C57BL/6JEi x C3SnHeSnJ (B6EiC3) F1 males. The animals were karyotyped using real-time quantitative PCR (qPCR), as previously described (Liu et al., 2003). The date of birth was designated as postnatal day zero (P0). The health and comfort of the animals were controlled by the veterinary service. The animals had access to water and food ad libitum and lived in a room with a 12:12 hour dark/light cycle. The experiments were performed in accordance with Italian and European Community law for the use of experimental animals and were approved by the Bologna University Bioethical Committee. In this study, all efforts were made to minimize animal suffering and to minimize 
the number of animals used.

\section{Immunohistochemistry}

Free-floating and paraffin-embedded sections of brains from euploid or Ts65Dn mice at 45 postnatal days were prepared as described in Guidi et al., (2014). Immunohistochemistry was conducted as previously described (Boda et al., 2011). Incubation with primary antibodies was performed overnight at $4^{\circ} \mathrm{C}$ in PBS with $5 \%$ normal goat serum and $0.3 \%$ Triton-X 100 . The high- sensitivity tyramide signal amplification kit (Perkin Elmer, Monza, Italy) was used in accordance with the manufacturer's instructions to reveal GPR $17^{+}$cells. The samples were incubated with secondary antibodies for $1 \mathrm{~h}$ at room temperature: goat anti-rabbit IgG or goat anti-mouse IgG conjugated to AlexaFluor ${ }^{8} 488$ were diluted 1:600. The nuclei were stained via a 20-min incubation at room temperature with Hoechst 33258 dye (1:10,000; Life Technologies). The slides were finally washed and mounted with Fluorescent Mounting Medium (Dako Italia, Milan, Italy). For MBP staining of paraffin-embedded samples, paraffin was removed using xylene, samples were re- hydrated with graded ethanol concentrations, and rinsed in water. To retrieve the antigenicity of the epitope, samples were maintained in $10 \mathrm{mM}$ sodium citrate buffer ( $\mathrm{pH}$ 6) containing $0.05 \%$ Tween ${ }^{\circledR} 20$ and underwent four cycles of heating in a microwave oven at $800 \mathrm{~W}$ for 4" each, separated by 1' of cooling. Samples were then stained using the Tyramide Signal Amplification kit according to manufacturer's instructions, except for blockage of nonspecific antigenic sites that was done overnight at $4^{\circ} \mathrm{C}$.

\section{Image analysis and quantification}

The internalization of GPR17 in HEK293 cells was quantified by measuring the immunofluorescence intensity of $\langle\mathrm{Nt}-\mathrm{GPR} 17$-stained cells before (time 0) and after incubation with agonists at $37^{\circ} \mathrm{C}$, followed by washes with glycine buffer to strip the antibody bound to the remaining cell surface-exposed receptors and further incubation at $37^{\circ} \mathrm{C}$ to allow receptor recycling (Fratangeli et al., 2013). At least three independent experiments were performed for each condition, and approximately 100 cells were examined in each experiment. The images were recorded using a Nikon E600 microscope (equipped with an AxioCam HRm; Zeiss Italia, Milano, Italy), an Axiovert 200M (Zeiss) confocal system equipped with a spinning disc (UltraVIEW acquisition system; Perkin Elmer Italia spa, Milan, Italy) or a Zeiss LSM510 Meta microscope with a Zeiss plan- NEOFLUAR 63x or 40x objective. To compare the double- or triple-stained patterns, the images from the fluorescein, rhodamine or Cy5 channels were acquired separately and superimposed. For the comparative analyses, the images were recorded using identical parameters. The images were exported as TIFF files for processing with Photoshop (Adobe Systems, Mountain View, CA, USA) and analyzed using ImageJ software.

To quantify the number of Myelin Basic Protein (MBP) or Myelin-Associated Glycoprotein (MAG)-positive cells in Oli-neu and OPC cultures, composite images were collected using the stitch option of the Volocity acquisition setup. Coverslips were scanned with a Zeiss Plan- NEOFLUAR 25x/0.80 objective using a PRIOR Proscan 3 motorized xy-stage. The stitched composite images were exported in TIFF format and processed with Photoshop or ImageJ. To analyze the number of positive cells after immunohistochemistry (Figs. 9 and 10), images of the whole hemisphere were recorded at 10X magnification under a Zeiss Axiovert 8400 microscope (Zeiss) equipped with a CCD camera 
module. The total number of positive cells in the whole hemisphere and in selected brain areas was counted using ImageJ software and normalized according to the number of counted fields (at least 50/sample; each field is $869.14 \mu \mathrm{m}$ wide and $650.28 \mu \mathrm{m}$ high, for an area of $565,186.5 \mu^{2}$ ). Representative images were examined with a laser scanning confocal microscope (LSM 510, Zeiss). Images were acquired and analyzed using the LSM Image Browser software (Zeiss). For MBP analysis in brain regions, comparable cutting sections of cerebral hemispheres from euploid or Ts65Dn mice immunostained for MBP were scanned using an Axiovert 200M confocal system equipped with a spinning disc and a motorized xy-stage. Multiple $\mathrm{x} / \mathrm{y}$ fields covering total area of individual brain hemisphere were acquired automatically with Volocity software using a focus map created in order to obtain the best focus for each field. The fields for each slice were then assembled automatically using the stitch option of the Volocity acquisition setup to form composite micrographs that were exported as TIFF file (Supp. Info. Fig. 8). For quantification, selected areas of corpus striatum and cortex were converted in binary images with Image $\mathbf{J}$ programme (using automatic thresholding) and the mean intensity quantified in a approximately equal areas. Cortex: euploid $=4.95 \mathrm{~mm}^{2}$; Ts65Dn $=5.07 \mathrm{~mm}^{2}$; corpus striatum: euploid $=5.90 \mathrm{~mm}^{2} ;$ Ts65Dn $=5.90 \mathrm{~mm}^{2}$.

\section{Statistical analysis}

Raw quantitative Western blotting data were normalized to the percentage of control (comparative Western blots) or to the percentage of $t=0$ (degradation assays) for each condition. The mean values and standard error of the mean for the indicated number of independent experiments were calculated followed by an unpaired Student's t-test to assess the statistical significance. Data were analyzed using GraphPad Prism software, and the results are expressed as mean values \pm s.e.m. Statistical significance was assessed using a two-tailed, unpaired Student's t- test or ANOVA test. 


\section{RESULTS}

\section{An intact PDZ-binding motif is required for the correct trafficking of GPR17}

To investigate the functional role of the putative PDZ-binding motif of GPR17, we introduced the following mutations into the C-terminus of wild-type mouse receptor (mGPR17-WT) in order to impair its interaction with putative PDZ domain proteins (Table 2; Lee and Zheng, 2010): i) an additional alanine residue positioned at the extreme end of the C-terminus (mGPR17-SELA); ii) a substitution that creates a stop codon before the PDZ-binding motif to delete the last four amino acids (mGPR17-stop); and iii) substitutions that give rise to an alanine residue instead of a serine at position P-2 (mGPR17AEL) or two alanine residues instead of a serine and a glutamate (mGPR17-AAL) at positions P-2 and P-1, respectively. The trafficking of mutant and wild-type GPR17 was analyzed after transient expression in HEK293 and in Oli-neu cells (Figs. 1, 2; Supp. Info. Figs. 1 and 2). The latter is an OL precursor cell line that was immortalized from E16 mouse brains (Jung et al., 1995; Winterstein et al., 2008) and recapitulates several features of differentiating OPCs in vitro. Oli-neu cells express many early OPC markers (including NG2, a cell surface chondrotin sulfate proteoglycan) and begin to differentiate and express GPR17 when cultured in cortical neuron-conditioned medium (CM; Fratangeli et al., 2013; Supp. Info. Fig. 5).

First, we investigated the sub-cellular distribution of mGPR17-WT and mutants in fixed cells by immunolabeling with antibodies directed against the C-terminal domain of GPR17 ( $\langle\mathrm{Ct}-\mathrm{GPR} 17$; Table 1 and Fratangeli et al., 2013 and refs. therein). At steady state, 48 hours after expression, mGPR17-WT was widely distributed on the cell surface of Oli-neu, as demonstrated by colocalization with NG2, and HEK293 cells (Supp. Info. Fig. 1). Conversely, all GPR17 mutants were mainly detected in discrete dotlike structures scattered throughout the cytoplasm and, to a much lesser extent, on the cell surface of Olineu (as revealed by a reduced colocalization with NG2) and HEK293 cells (see Supp. Info. Fig. 1 for GPR17-SELA and data not shown for other receptor mutants).

To track GPR17 internalization, we took advantage of an antibody raised against the 17 extracellular N-terminal domain of the receptor (named $\mathrm{Nt}-\mathrm{GPR} 17$, Table 1) previously utilized to analyze the endocytic trafficking of endogenous GPR17 in Oli-neu cells (Fratangeli et al., 2013). We therefore labeled living transfected HEK293 cells at $37^{\circ} \mathrm{C}$ for $30 \mathrm{~min}$ with $\langle\mathrm{Nt}-\mathrm{GPR} 17$, as previously described (Fratangeli et al., 2013). mGPR17-WT was still mainly detected on the cell surface, as revealed by colocalization with anti-cadherin antibodies used to decorate HEK293 plasma membrane (Fig. 1). Conversely mGPR17-SELA (Fig. 1), -stop, -AAL and -AEL (Supp. Info. Fig. 2) were mostly localized in intracellular vesicles. Colocalization with the transferrin receptor (TfR) revealed that a number of these structures corresponded to endocytic vesicles. Colocalization of mGPR17-WT and TfR-positive vesicles was also observed (Fig. 1, Supp. Info. Fig. 2), in line with previous observations (Fratangeli et al., 2013). Conversely, no colocalization with markers of either the Golgi apparatus or of the endoplasmic reticulum was detected (data not shown). Taken together, these findings indicate that alteration of the PDZ-binding motif impairs GPR17 trafficking.

To further characterize the defects in the transport of mutant receptors, we labeled surfaceexposed receptors for $30 \mathrm{~min}$ at $4^{\circ} \mathrm{C}$ with the $\langle\mathrm{Nt}-\mathrm{GPR} 17$ antibody and stimulated their internalization/desensitization by incubation with a GPR17 agonist (UDP-glucose). After acid washing (glycine buffer, $\mathrm{pH} 2.8$ ) to strip the antibodies bound to the receptors that remained on the cell surface, 
we re-incubated the cells in the absence of agonist for 10 or $20 \mathrm{~min}$ at $37^{\circ} \mathrm{C}$ and then fixed, permeabilized and labeled them with anti-rabbit IgG conjugated to Cy2. Immunofluorescent micrographs obtained by spinning disc confocal microscopy and quantitative analysis of immunofluorescence intensity showed that similar amounts of mGPR17-WT and mGPR17-SELA were detected on the cell surface after labeling at $4^{\circ} \mathrm{C}$, i.e. when internalization is blocked (Fig. 2A, E, I). Upon activation with UDP-glucose, both receptors were internalized in endocytic compartments, as revealed by the distribution of antibodylabeled receptors in vesicles detected mainly at the perinuclear region of cells (Fig. 2B, F). These results are consistent with our previous data showing that endogenous GPR17 is rapidly internalized upon stimulation and colocalize with markers of endocytic pathway (Fratangeli et al., 2013). Moreover, after agonist removal receptors are sorted in the endocytic compartment and partially directed to lysosomes for degradation whereas a fraction is sorted in a Rab4-positive compartment for plasma membrane recycling (Fratangeli et al., 2013). In line with these data, 10 or $20 \mathrm{~min}$ after UDP-glucose removal a decrease in mGPR17- WT intracellular immunostaining was observed in transfected HEK293 cells (Fig. 2C, D, L). Conversely, 30\% more mGPR17-SELA than mGPR17-WT was still retained within the cells (Fig. 2G, H, L), thus suggesting that mutation of the PDZ motif disrupted the endocytic trafficking of GPR17.

To amplify GPR17 staining, we transfected FLAG-tagged isoforms of human GPR17 (FLAGhGPR17) -WT or -SELA into HEK293 cells. In these experiments, we followed the internalization and intracellular fate of FLAG-hGPR17 by in vivo labeling with a mouse antibody directed against the FLAG-epitope, which increases the sensitivity of the staining procedure with respect to the $\langle\mathrm{Nt}-\mathrm{GPR} 17$ antibody. As shown in Figure 3, agonist treatment led to a pronounced redistribution of both antibodylabeled FLAG-hGPR17-WT and FLAG-hGPR17-SELA from the plasma membrane to intracellular puncta (indicating ligand-induced endocytosis), but $15 \mathrm{~min}$ after agonist removal FLAG-hGPR17-SELA exhibited greater immunoreactivity inside the cells compared with WT-labeled receptors. In addition, thanks to the higher sensitivity of the anti-FLAG- antibody, re-distribution of FLAG-labeled receptors from the intracellular compartment to the cell surface (Fig. 3 arrows) was also detected, suggesting a more efficient recycling of wild-type compared with mutant GPR17.

Taken together, these findings indicate that the PDZ-binding motif is functionally required for GPR 17 endocytic trafficking and plasma membrane recycling through interactions with PDZ domain-containing proteins to be identified.

\section{SNX27 directly interacts with the PDZ-binding motif of GPR17 and is required for receptor recycling to the cell surface}

On the basis of above data suggesting that recycling of GPR17 is affected by disruption of its PDZ-binding motif, we focused our attention on PDZ domain-containing proteins. We chose SNX27 since it is specifically required for plasma membrane recycling of a number of receptors (Lunn et al., 2007; Lauffer et al., 2010; Balana et al., 2011; Temkin et al., 2011; Steinberg et al., 2013; Loo et al., 2014). In addition we analyzed the possible interaction of GPR17 with NHERF1 that has been reported to affect the trafficking of purinergic receptors, including the P2Y12 subtype (Nisar et al., 2012; see Introduction).

Double-immunolabeling of Oli-neu and primary OPC cultures (Fumagalli et al., 2011) with 
polyclonal antibodies directed against NHERF1 or SNX27 and NG2 or Olig2 demonstrated that both proteins are expressed in cells of the OL lineage (Supp. Info. Fig. 3). In Oli-neu cells, NHERF1 immunostaining was associated with the plasma membrane, as demonstrated by colocalization with NG2, and appeared to be concentrated in filopodia/microvilli. This distribution was similar to that observed in HEK293 cells, and in primary OPCs (Supp. Info. Fig. 3A, B, D) and is consistent with data showing that NHERF proteins interact with the ezrin/radixin/moesin (ERM) family of actin-binding proteins (Reczek et al., 1997; Terawaki et al., 2006). Immunostaining for SNX27 in Oli-neu cells and differentiating OPCs was detected in dot-like structures scattered throughout the cytoplasm (Supp. Info. Fig. 3E; Fig. 4F, G), as previously observed in other cell types (Cai et al., 2011). Accordingly, Western blot analysis confirmed the expression of NHERF1 and SNX27 proteins in Oli-neu extracts (see Fig. 4C).

To assess whether NHERF1 and SNX27 interact with the GPR17 PDZ-binding motif, Oli- neu cell lysates were incubated with Sepharose beads conjugated to either a peptide of 19 amino acids corresponding to the C-terminal end of GPR17 and containing the PDZ-binding motif (CT, Fig. 4A) or to a similar peptide lacking the PDZ-binding motif ( $\triangle \mathrm{CT}$, Fig. 4A). After incubation and extensive washing, the bound proteins were eluted and analyzed by means of Western blotting. Results indicated that neither peptide could isolate detectable amounts of NHERF1, whereas CT isolated at least 10 times more SNX27 than $\triangle \mathrm{CT}$ (Fig. 4B, C). Additionally, His-SNX27 purified from BL21DE3 E. coli lysates (Fig. 4D) specifically bound to CT but not to the ØCT peptide, thus demonstrating that SNX27 directly interacts with GPR17. To precisely characterize SNX27 and GPR17 interaction, we mutagenized histidine 114 that is part of the PDZ domain of human SNX27, into an alanine. This point mutation in the < helix of the SNX27-PDZ domain is predicted to disrupt a critical hydrogen bond with the serine/threonine residue located at the -2 position of a PDZ- interacting motif (Lauffer et al., 2010). Notably, only His-SNX27 (WT) but not His-SNX27 H114A (H/A) from BL21DE3 E. coli extracts bound to the CT peptide (Fig. 4E). Taken together, these observations demonstrate that the PDZ domain of SNX27 specifically interacts with the C-terminal PDZ-binding motif of GPR17.

Next, we analyzed whether GPR17 colocalizes with SNX27 in the recycling endosomes after endocytosis. To achieve this goal, Oli-neu cells (Fig. 4F) or rat primary OPCs (Fig. 4G) were incubated in CM (neuron-conditioned medium; Fratangeli et al., 2013) or neurobasal medium (Fumagalli et al., 2011), respectively, to stimulate cell differentiation and GPR17 expression. After $48 \mathrm{~h}$, cells were labeled in vivo at $4^{\circ} \mathrm{C}$ with $\left\langle\mathrm{Nt}-\mathrm{GPR} 17\right.$ or $\left\langle\mathrm{Nt}-\mathrm{rGPR} 17\right.$, respectively, stimulated for 30 minutes at $37^{\circ} \mathrm{C}$ with UDP-glucose, and then incubated for $10 \mathrm{~min}$ in the absence of the agonist. After acid washing, cells were fixed and double-immunolabeled with a goat anti-SNX27 antibody (followed by an anti-goat IgG antibody) and an anti-rabbit IgG to detect the internalized receptors. Spinning disc confocal microscopy analysis clearly showed that endogenous GPR17 colocalized with SNX27 in a number of vesicles scattered in the cytoplasm (Fig. 4F, G). Moreover, in line with our previous data showing that an aliquot of GPR17 undergoes to constitutive endocytosis (Fratangeli et al., 2013), we found that GPR17 still colocalized with SNX27 in a number of endocytic vesicles after internalization in the absence of agoniststimulation (Supp. Info. Fig. 4). Altogether these data confirm the interaction between GPR17 and SNX27 in native in vitro systems.

It has been reported that SNX27 knock-down, while abolishing receptor recycling to the plasma membrane, can increase sorting of internalized receptors to degradative compartments, such as 
lysosomes and the proteasome (Lauffer et al., 2010; Wang et al., 2013). To test whether SNX27 downregulation also promotes GPR17 degradation, we silenced SNX27 in Oli-neu cells by RNA interference and analyzed the levels of expression of endogenous GPR17. In preliminary experiments, four distinct shRNAs targeting different regions of SNX27 mRNA and expressing GFP (utilized as reporter marker of transfection in fluorescence or Western blot analysis) were transfected into Oli-neu cells. Twenty-four hours after transfection, cells were incubated in CM medium to promote GPR17 expression and differentiation, as described above. Evaluation of the percentage of cells expressing GPR17 demonstrated that, after $48 \mathrm{~h}$ in differentiating conditions, more than $70 \%$ of the whole cell culture expressed the receptor (Supp. Info. Fig. 5). We therefore decided to collect cell lysates at this time point. Western blot analysis revealed that shRNA-3 (referred to as shRNA-SNX27) was the most effective in knocking down SNX27, whose levels were reduced to $33.36 \pm 14.44 \%$ when compared to cells transfected with scrambled shRNA (shRNA-Scr; Fig. 5A). Thus, this plasmid was used in all of the subsequent experiments. Western blot analysis of cell lysates showed that the amount of GPR17 was significantly reduced (to $49.20 \pm 8.64 \%$ ) in the SNX27-silenced Oli-neu cells in comparison to cells that were transfected with scrambled shRNA. The effect of SNX27 silencing on GPR17 appeared to be specific, as cytoskeletal (actin), Golgi-membrane associated (GS28) proteins or plasma membrane cadherins (i.e. proteins that may also undergo recycling after endocytosis but do not contain PDZ-binding motifs, Le et al., 1999) were unaffected (Fig. 5A). In line with data showing that SNX27 knockdown increases the delivery of target proteins to lysosomes (Lauffer et al., 2010; Wang et al., 2013), we found that levels of GPR17 in SNX27 silenced Oli-neu were partially rescued by treatment with the lysosomal inhibitor $\mathrm{NH} 4 \mathrm{Cl}$, thus indicating an accelerated rate of receptor degradation after SNX27 knock-down (Fig. 5B) due to alterations in receptor recycling to the plasma-membrane.

To further demonstrate that SNX27 knock-down causes defective GPR17 recycling, we followed its trafficking in SNX27-silenced cells. Due to the low levels of endogenous GPR17 in Oli-neu cells after SNX27 silencing, the trafficking of endogenous receptors could not be investigated efficiently. To overcome this problem, we cotransfected Oli-neu cells with scrambled shRNA or shRNA-SNX27 together with a plasmid encoding FLAG-hGPR17-WT and followed the trafficking of over-expressed hGPR17 after in vivo labeling with an anti-FLAG antibody (see also above). After receptor immunolabeling at $4^{\circ} \mathrm{C}$, stimulation with agonist followed by glycine buffer washing to strip antibodies from receptors still exposed on the cell surface, and agonist removal to promote receptor recycling, cells were fixed and double-immunolabeled with anti-mouse IgG antibody (to detected hGPR17-FLAG) and an antibody against NG2 (to decorate cell membrane). Immunofluorescence micrographs were acquired using a spinning disc confocal microscope, and cells expressing similar amounts of the GFP fluorescent marker were acquired and subjected to quantitative analysis (Figs. 6 and 7). A similar GPR17 immunoreactivity was detected in shRNA-Scr- and shRNA-SNX27-transfected cells after UDP-glucose stimulation, with agonist-induced receptor internalization. However, after agonist removal a lower fraction of the receptor was recycled to the cell surface in SNX27-silenced cells, as demonstrated by the absence of colocalization with NG2 (Fig. 6, right column). A quantitative analysis of GPR17 immunoreactivity detected inside of the cells (intracellular) or on the cell surface (membrane) is shown in Figure 7. Data are expressed as percentage of total immunoreactivity (i.e., the sum of intracellular and membrane immunolabeling set to $100 \%$ ) at time 0 (i.e, agonist stimulation, followed by glycine washing) 
or $10 \mathrm{~min}$ after agonist removal. Results demonstrate that at time 0 the majority of GPR17 immunostaining is detected intracellularly in both cells transfected with shRNA-Scr and in cells transfected with shRNA-SNX27. Conversely, $10 \mathrm{~min}$ after UDP-glucose removal a significant increase in receptor staining on the membrane of shRNA-Scr-transfected cells was observed, whereas GPR17 was retained intracellularly in SNX27-silenced cultures. Taken together, these data confirm that SNX27 knock-down impaired the plasma membrane recycling of GPR17.

\section{Loss of SNX27 accelerates OL differentiation}

On the basis of these results, and given the role of GPR17 in OPC differentiation, we investigated whether SNX27 down-regulation alters the processes underlying OL differentiation by analyzing the expression of myelin proteins in Oli-neu after shRNA transfection (Fig. 8). Oli-neu cells represent a wellcharacterized in vitro model to investigate OL differentiation (Fratangeli et al., 2013). As shown above, when maintained in Sato medium, undifferentiated Oli-neu cells express very low levels of GPR17 and almost no myelin proteins (Supp. Info. Fig. 5; Fratangeli et al., 2013). After incubation in CM Oli-neu begin to express GPR17 and differentiate towards a more mature phenotype, as shown by the appearance of $\mathrm{MBP}^{+}$cells, with almost $70 \%$ and approximately $90 \%$ of the cell population expressing GPR17 at 48 and $72 \mathrm{~h}$ of differentiation, respectively (Supp. Info. Fig. 5 and Fratangeli et al., 2013). At later times (96-120 h) cells expressing MBP strongly increase in number, with a parallel decline in the number of GPR $17^{+}$cells (Fratangeli et al., 2013; data not shown). Based on these data, we chose to compare the expression of GPR17 and myelin proteins in shRNA-Scr or shRNA-SNX27 transfected cells $48 \mathrm{~h}$ after differentiation in CM, corresponding to high GPR17 expression paralleled by low levels of MBP.

At this time point, confocal microscopy analysis of shRNA-Scr-trasfected Oli-neu (identified by their GFP expression) showed that these cells expressed high levels of GPR17 and did not coexpress the myelin proteins MAG and MBP (Fig. 8A, a-b'), in line with results shown for untransfected Oli-neu (Supp. Info. Fig. 5; Fratangeli et al., 2013). In contrast, a significant increase in both MAG and MBP expression was detected in shRNA-SNX27-transfected cells, in which GPR17 was down-regulated (Fig. $8 \mathrm{~A}$, c-d''). Specifically, 33.6 $\pm 2.57 \%$ of the transfected $\mathrm{GFP}^{+}$cells were $\mathrm{MBP}^{+}$in SNX27-silenced Olineu compared to $12 \pm 2.86 \%$ positive cells in shRNA-Scr-trasfected Oli-neu (Fig. 8B). Immunoblotting analysis confirmed these data by demonstrating a 4-fold higher expression level of the myelin protein MAG in SNX27-silenced cells compared to shRNA-Scr-trasfected cells (Fig. 8C). Taken together, these findings demonstrate that loss of SNX27 in differentiating Oli-neu cells does not only down-regulate GPR17 expression, but also accelerates cell differentiation towards fully myelinating phenotypes.

We further investigated the effects of SNX27 knock-down on cell differentiation using primary mouse OPC cultures. Immunoblotting analysis confirmed that SNX27 silencing resulted in a significant down-regulation of GPR17 (69.77 \pm 8.39$)$ compared to control (Fig. 8D). Furthermore, a quantitative analysis of immunolabeled OPCs using confocal microscopy revealed an increasing trend in the number of mature $\mathrm{MAG}^{+} \mathrm{OLs}$ in shRNA-SNX27-transfected cultures compared with shRNA-Scr-transfected cells (Fig. 8D). Overall, these data confirm that SNX27 knock-down affects GPR17 expression and the timing of OL maturation also in OPCs that natively express the receptor. To shed light on the possible molecular mechanisms underlying SNX27 effects on OL differentiation, we analyzed the Id2 (Inhibitor of DNA binding 2) and mTOR (mammalian Target of Rapamycin)/GRK2 (G protein-coupled receptor 
kinase 2) pathways, which have been demonstrated to control both OL differentiation and GPR17 expression (Chen et al., 2009; Tyler et al., 2011; Mitew et al., 2014; Fumagalli et al., 2015). Id2 localization to the nuclear and cytoplasmic compartments was analyzed by Western blotting analysis in shRNA-Scr- and shRNA-SNX27- transfected Oli-neu cells. As shown in Fig. 8E, a partial relocalization of Id2 from the nucleus to the cytoplasm was observed in SNX27-silenced (23.48 $55.53 \%$ nuclear; $76.93 \pm 5.94 \%$ cytosolic) compared to shRNA-Scr transfected Oli-neu cells $(44.77 \pm 0.70 \%$ nuclear; $55.23 \pm 0.71 \%$ cytosolic; $n=2$ independent experiments). Conversely, no major changes in the expression of GRK2 or in the phosphorylation state of mTOR were observed (Supp. Info. Fig. 6).

\section{Reduced SNX27 levels in the brains of mice modeling Down syndrome correlate with defects in OL maturation and myelination pattern}

Based on data in the literature showing SNX27 down-regulation followed by degradation of AMPA/NMDA receptors in DS brains (Wang et al., 2013 and 2014), we deemed it interesting to investigate whether GPR17 could be altered in the brains of 45-day-old Ts65Dn mice (a wellcharacterized model of human trisomy 21 ; Reeves et al., 1995) and age-matched euploid mice. Firstly we demonstrated that, in line with literature data (Wang et al., 2013), SNX27 expression was significantly lower in brain lysates from Ts65Dn mice than in lysates from euploid animals (Supp. Info. Fig. 7). We next evaluated the expression of the transcription factor Olig2, a master regulator of OL development and one of the trisomic genes in DS (Mitew et al., 2014). Our analyses in coronal sections of brain hemispheres of 45-day-old mice revealed a significant increase in Ts65Dn mice of the total number of Olig2- expressing cells, with $105.32 \pm 4.88$ and $133.31 \pm 8.95$ Olig2 ${ }^{+}$cells/optical field (mean of 6-7 brain slices from 4 independent animals; **P $<0.01$, unpaired two- tailed Student's t-test) counted in euploid and Ts65Dn brain slices, respectively. GPR $17^{+}$cells represent a subpopulation of OPCs, as demonstrated by their typical morphology and colocalization with Olig2 (Fig. 9A; Boda et al., 2011). Notably, we found that Ts65Dn mice showed a significant reduction in the number of GPR17-expressing cells, both in the whole hemisphere and in the cortex and thalamus, with a trend in the hippocampus (Fig. 9A, B).

We next analyzed the expression of markers of advanced OL maturation. Interestingly, a significant increase in the number of OLs expressing $\mathrm{CC} 1$, a typical marker of advanced stages of maturation (Luo et al., 2014; Sachs et al., 2014), was observed in the whole brain hemisphere of Ts65Dn mice (Fig. 9C, D left), and in all the analyzed brain areas (Fig. 9D, right). This is in agreement with our in vitro data showing accelerated OPC maturation following SNX27 and GPR17 down-regulation.

To reconcile these results with previous data showing hypo- (and not hyper-) myelination in human trisomic brains (Abraham et al., 2012), we also evaluated the expression of GST $\pi$ and of MBP, which in vivo are expressed by fully myelinating OLs at more mature terminal stages of differentiation with respect to CC1 (Boda et al., 2011; Viganò et al., 2016). A significant reduction in the number of GST $\pi$-expressing OLs was observed in Ts65Dn mice (Fig. 10A, B), suggesting myelination defects in DS brains. In the case of MBP, protein expression was evaluated in the grey matter (i.e., selected areas of cortex and corpus striatum; Fig. 11) and in the corpus callosum (Supp. Info. Fig. 8) by densitometric analysis after immunohistochemistry. These analyses clearly demonstrated a significant decrease of MBP immunoreactivity in the grey matter of brains from Ts65Dn mice compared to euploid brains (with a reduction of $28 \%$ and $35 \%$, in the cortex and corpus striatum, respectively; 6 slices from 3 
mice/genotype). A similar reduction was observed in the corpus callosum of Ts65Dn mice (Supp. Info. Fig. 8). Results were confirmed by Western blotting analysis, showing a reduction in the two major isoforms of MBP in brain lysates of Ts65Dn compared to euploids (45\% and 55\% reduction for the protein bands at $14 \mathrm{kDa}$ and $18.5 / 17 \mathrm{kDa}$, respectively).

Overall, data in Ts65Dn brains suggest that GPR17 down-regulation, possibly linked to the reduced SNX27 expression, is accompanied by an accelerated maturation of OPCs towards more mature $\mathrm{CC}^{+}$OLs. Nevertheless, these $\mathrm{CC}^{+}$cells cannot reach terminal maturation, possibly due to the reduced number of axons to be myelinated, leading to an overall reduced myelin content that could further contribute to the intellectual and motor deficits of these mice. 


\section{DISCUSSION}

In vivo and in vitro studies have shown that GPR17 expression affects the timing of OL maturation. After the stage of immature OLs, GPR17 down-regulation triggers the differentiation of OLs toward more mature phenotypes, whereas its sustained, forced expression inhibits their terminal maturation (Chen et al., 2009; Fumagalli et al., 2015 and refs. therein). Stringent regulation of GPR17 expression is therefore important in controlling OL differentiation and myelination. In addition to transcriptional and post-transcriptional controls, GPR17 regulation at the post-translational level by intracellular trafficking and degradation may also cooperate in modulating its expression and, in turn, OPC maturation. In this respect, a number of findings highlight the importance of endocytosis in regulating signal transduction during development and cell differentiation. For example, following activation by Wnt-ligands, Frizzled is internalized (and subsequently degraded) via a clathrin-mediated pathway, and alterations in this process induce aberrant embryonic development (Piddini et al., 2005; Rives et al., 2006; Seto and Bellen, 2006; Yu et al., 2007). Erythropoietin receptor endocytosis and its subsequent sorting into degradative compartments has been shown to be a prerequisite for the completion of erythrocyte differentiation, suggesting that receptor down-regulation via lysosomal degradation is necessary to allow the progression of cells toward terminal maturation (Walrafen et al., 2005). Our previous data showed that after endocytosis GPR17 is partially degraded or recycled to the plasma membrane (Fratangeli et al., 2013). The mechanisms underlying sorting of receptors into recycling endosomes play an important role in preserving the number of receptors exposed to the cell surface, which in turn, obviously impacts on receptor function.

To further understand these mechanisms and their role in OL differentiation in physiological conditions, as well as in diseases that are associated with dysregulated myelination, in the present study we investigated the trafficking of GPR17 endocytosis by focusing our attention on a putative PDZbinding motif in the $\mathrm{C}$-terminal region of the receptor and on its possible interactors. Our findings show that: i) mutations of the GPR17 PDZ-binding motif impair receptor trafficking and recycling to the plasma membrane; ii) SNX27, a member of the retromer complex involved in protein trafficking from early endosomes back to the plasma membrane (Temkin et al., 2011; Steinberg et al., 2013; Gallon et al., 2014; McGough et al., 2014), interacts with the C-terminal domain of GPR17 and is required for its recycling; iii) silencing of SNX27 significantly increases GPR17 degradation, and this correlates with increased expression of the myelin proteins MAG and MBP and with accelerated OL differentiation in vitro. In agreement with these data, the number of GPR17-expressing cells was greatly diminished in parallel with an increased number of mature $\mathrm{CC}^{+} \mathrm{OLs}$ in the post-natal brains of Ts65Dn mice, a mouse model of DS exhibiting decreased levels of SNX27 by the expression of trisomic mir-155 (Wang et al., 2013 and 2014). On the other hand our findings reveal that myelination is decreased in Ts65Dn mice, in line with previous data showing hypomyelination in human DS brains (Abraham et al., 2012; see also below). Altogether these data highlight a previously unknown role for SNX27 in GPR17 trafficking and OL differentiation. Whereas a great number of studies has reported a role of SNX27 in controlling glutamate receptor and ion channel expression with important implications in synaptic transmission (Balana et al., 2011; Wang et al., 2013, 2014; Hussain et al., 2014; Loo et al., 2014; Munoz and Slesinger, 2014; Damseh et al., 2015), very few data are available on the physiological and pathological functions of SNX27 in other cell types (Singh et al., 2015). Thus, these findings extend our knowledge on the 
physiological functions modulated by SNX27 and, for the first time, indicate a crucial role for this protein in OL development.

\section{SNX27 is required for GPR17 recycling and stability}

After agonist activation, GPR17 is rapidly phosphorylated by G protein-coupled receptor kinases, binds to arrestins, undergoes clathrin-dependent endocytosis (Fratangeli et al., 2013; Hennen et al., 2013; Daniele et al., 2014; Fumagalli et al., 2015) and is finally delivered to either lysosomes for degradation or to a Rab4-positive compartment for recycling to the cell surface (Fratangeli et al., 2013). Here, we demonstrate that the PDZ-binding motif at the C-terminus of GPR17 is required for its endocytic trafficking. Human or mouse GPR17 constructs carrying mutations that alter the PDZ-binding motif sequence are retained in endocytic vesicles not because of a defect in plasma membrane localization or endocytosis (as revealed by the analysis of receptor internalization after UDP-glucose treatment), but owing to the inhibition of cell surface recycling. Approximately 30\% more mGPR17-SELA than wildtype receptor was retained intracellularly after agonist stimulation, which is consistent with our previous finding that $\sim 30 \%$ of internalized endogenous GPR17 is recycled to the plasma membrane after UDPglucose removal (Fratangeli et al., 2013). Moreover, while wild-type FLAG-hGPR17 can be re-exposed at the cell surface $15 \mathrm{~min}$ after agonist removal, receptors carrying mutations in the $\mathrm{C}$-terminal domain are not.

In our search for interactors, we found that the PDZ-binding motif of GPR17 interacts with SNX27. A substantial amount of experimental evidences supports our conclusions. First, our in vitro data show that SNX27 specifically binds to the intact C-terminal domain of GPR17. Additionally, a point mutation disrupting the PDZ ligand association form of SNX27 abolishes the binding of SNX27 to the PDZ binding motif of GPR17. In agreement with the biochemical data, we found that internalized GPR17 colocalizes with SNX27 not only after agonist stimulation, but also after constitutive endocytosis; SNX27 is normally recruited by early endosomes and retromer tubules that also contain Rab4 (Lauffer et al., 2010; Temkin et al., 2011; Steinberg et al., 2013). Notably, Rab4-positive compartments are known to be involved in the rapid recycling of GPR17 to the plasma membrane (Fratangeli et al., 2013). The functional relevance of this interaction was supported by the observation that wild-type GPR17 was retained in endocytic vesicles after SNX27 knock-down in a similar manner to the GPR17 mutants lacking a functional PDZ-binding motif. Overall, these findings indicate that SNX27 plays an important role in GPR17 recycling, a conclusion that is also supported by the observation that SNX27 knock-down alters the stability of GPR 17.

\section{SNX27 is crucial for preserving GPR17 levels and the timing of myelin protein expression}

SNX27 is therefore essential for preventing lysosomal degradation and maintaining the correct levels of GPR17 in OLs during differentiation. Loss of SNX27 affects the onset of maturation insofar as SNX27 down-regulation induces OLs to express larger amounts of the myelin proteins MAG and MBP earlier than cells with normal SNX27 levels. These effects on myelin proteins could be linked to the decreased levels of GPR17, as it has been shown to modulate OL differentiation via a mechanism which involves nuclear accumulation of Id2, which, when accumulated in the nucleus, can sequester Olig1/Olig2, thus blocking MBP expression and OL maturation (Mitew et al., 2014). Conversely, when 
Id 2 is mostly localized to the cytoplasm, Olig1/Olig2 promote the expression of myelin proteins, and stimulate immature OL to proceed towards a mature phenotype. Interestingly, we found that Id 2 is enriched in the cytoplasm of Oli- neu cells following SNX27 down-regulation, thus suggesting a contribution of this signaling pathway to the observed effects in OL maturation. Conversely, the mTOR pathway that is known to increase GPR17 desensitization via down-regulation of GRK2 (Fumagalli et al., 2015) is not affected by SNX27 knock-down. Globally, these results are consistent with previous findings showing that the down-regulation of GPR17 is required for myelin protein expression and complete OL differentiation, while its sustained over-expression, a condition that is also observed in demyelinating lesions in the central nervous system, inhibits OL maturation (Chen et al., 2009). Moreover, our data suggest that SNX27 may affect OL maturation by controlling GPR17 recycling to the plasma membrane. However, several studies have reported that SNX27 may interact with a number of plasma membrane receptors and ion channels (Steinberg et al., 2013; Wang et al., 2013), including the AMPA receptor GluR1/GluR2 subunits and the NMDA receptor NR1/NR2 subunits that are expressed not only in neurons, but at lower levels also in cells of the OL lineage (Hossain et al., 2014; Li et al., 2013). On this basis, we cannot rule out that other molecules might be affected by SNX27 silencing as well, and contribute to the observed impairment of myelin protein expression. Further studies will be needed to explore this possibility. Our in vitro findings may have implications in case of diseases caused by abnormal GPR17 expression and signaling such as multiple sclerosis (Chen et al., 2009), where disruption of the interaction between the SNX27 PDZ domain and the PDZ-binding motif of GPR17 may contribute to disease development. In this respect, it has been previously suggested that Dishevelled, a small molecule disruptor of PDZ domain interactions, and an essential effector protein in the Wnt signaling pathway, may be therapeutically useful in prostate cancer (Grandy et al., 2009). Moreover, it has been shown that variants of a number of receptors or scaffold proteins carrying polymorphisms within or near either the PDZ domain or the PDZ-binding motif are pathologically relevant in autism, Usher syndrome, and patients predisposed to mild bleeding (Kalay et al., 2005; Mejias et al., 2011; Nisar et al., 2012).

\section{In vivo role of SNX27: what we can learn from a model of Down syndrome}

Finally, we decided to explore OL differentiation and myelination in a pathological setting in which SNX27 levels are affected. A number of studies have demonstrated that dysfunctional members of the retromer complexes that regulate endosomal sorting (including the vacuolar protein sorting-family and other core components, such as VPS35 and VPS26) are risk factors for neurodegenerative diseases, including Alzheimer's and Parkinson's diseases (Small et al., 2005; Vilariño-Güell et al., 2011; Zimprich et al., 2011) and frontotemporal lobar degeneration (Hu et al., 2010). No mutations in the PDZ-binding motif of GPR17 have been reported yet. However, a mutation/deletion in the SNX27 gene has recently been found in a patient with epilepsy and neurodegeneration (Damseh et al., 2015). Furthermore, Wang et al. (2013) showed that triplication of the miR-155 gene and its over-expression in trisomic brains impaired the synthesis of the C/EBP $\beta$ transcription factor required for SNX27 expression and that increased levels of miR-155 reduced the expression of SNX27. Notably, down-regulation of SNX27, in turn, caused significant endocytic mis-sorting and down-regulation of glutamate receptors in DS brains. Therefore, we thought it interesting to investigate whether GPR17 expression was perturbed in Ts65Dn 
mice, and indeed detected fewer GPR $17^{+}$cells in some regions of Ts65Dn brains compared to control. The counterpart of this reduction was an increase in the number of $\mathrm{CC}^{+}$OLs in various brain regions. These cells are mature, but not fully myelinating OLs (Boda et al., 2011; Viganò et al., 2016). In fact, despite the increased number of $\mathrm{CC}^{+} \mathrm{OLs}$, we found a reduced number of $\mathrm{GST}^{+}$cells (i.e. fully myelinating OLs), paralleled by reduced levels of MBP, suggesting impairment in the myelination process in Ts65Dn mice.

Recent evidence has suggested myelination defects in human trisomic brains (Abraham et al., 2012). Consistently, children with DS exhibit subnormal conduction velocity in peripheral nerves (Brandt and Rosén, 1995), prolonged latencies of somatosensory evoked potentials (Chen and Fang, 2005) and slower interhemispheric transmission (Heath et al., 2007). Myelination implies a high degree of specificity and is regulated by the axon size, repulsive and permissive signals (Simons and Lyons, 2013), neuronal electrical activity and axonal release of neurotransmitters such as adenosine and glutamate that foster the local synthesis of myelin proteins at the very sites of axon-OPC physical contacts (Stevens et al., 2002; Wake et al., 2011). It should be noted that the DS brain is characterized by a reduced number of neurons (Contestabile et al., 2007; Guidi et al., 2008; Guidi et al., 2011), and therefore of axonal targets. It remains to be established whether the reduced number of myelinating GST $\pi^{+}$cells and the defective MBP expression observed in the Ts65Dn mouse model are due to trisomy-linked alteration in the differentiation program leading from $\mathrm{CC}^{+}$to $\mathrm{GST}^{+} \mathrm{OLs}$ (fully myelinating cells) or whether they are linked to the overall reduced number of neurons with a consequent reduction of axonal targets. In addition, DS pathology is the result of a complex genetic background leading to the altered expression of many different genes that may contribute to the resulting phenotype. Therefore, we cannot exclude that other mechanisms may intervene to induce the myelination defects observed in animal models and in patients.

\section{Conclusions}

Taken together, our data reveal, for the first time, a crucial role of SNX27 in modulating GPR17 levels by means of a post-translational mechanism and highlights the relationship between the trafficking of the receptor through the endomembrane system and OL differentiation. We additionally provide novel evidence of impairment of GPR17 expression and OL maturation in a mouse model of DS that is characterized by SNX27 down-regulation. This suggests that myelination defects may contribute to the brain functional alterations that characterize the trisomic condition and, possibly, other pathologies characterized by impairment of the SNX27-GPR17 system.

\section{Acknowledgements}

We are grateful to Jacqueline Trotter for kindly providing the Oli-neu cells, Roberta Benfante and Nica Borgese for helpful suggestions and discussions. We would like to extend special thanks to the Monzino Foundation, Milan, Italy, for the gift of the Zeiss LSM510 Meta confocal microscope and the Axiovert 200M confocal system equipped with a spinning disc (Perkin Elmer Life Sciences). This study was supported by the Cariplo Foundation (Ref. No. 2012-0546), the CNR Research Project on Aging and Regione Lombardia Project MbMM-Convenzione No. 18099/RCC. VM and FV were supported by fellowships sponsored by the Cariplo Foundation. AU is a post-doctoral student supported by the 
University of Milan. MB was a fellow of the Fratelli Confalonieri Foundation and is currently a fellow of the Umberto Veronesi Foundation.

\section{Conflict of interest}

The authors declare that they have no conflict of interest. 


\section{REFERENCES}

- Abraham H, Vincze A, Veszpremi B, Kravjak A, Gomori E, Kovacs GG, Seress, L. 2012. Impaired myelination of the human hippocampal formation in Down syndrome. Int $\mathrm{J}$ Dev Neurosci 30:147- 158. Ardura JA, Friedman PA. 2011. Regulation of G protein-coupled receptor function by $\mathrm{Na}+\mathrm{H}+$ exchange regulatory factors. Pharmacol Rev 63:882-900.

- Balana B, Maslennikov I, Kwiatkowski W, Stern KM, Bahima L, Choe S, Slesinger PA. 2011. Mechanism underlying selective regulation of $\mathrm{G}$ protein-gated inwardly rectifying potassium channels by the psychostimulant-sensitive sorting nexin 27. Proc Natl Acad Sci USA 108:58315836.

- Boda E, Viganò F, Rosa P, Fumagalli M, Labat-Gest V, Tempia F, Abbracchio MP, Dimou L, Buffo A. 2011. The GPR17 receptor in NG2 expressing cells: focus on in vivo cell maturation and participation in acute trauma and chronic damage. Glia 59:1958-1973.

- Brandt BR, Rosén I. 1995. Impaired peripheral somatosensory function in children with Down syndrome. Neuropediatrics 26:310-312.

- Cai L, Loo LS, Atlashkin V, Hanson BJ, Hong W. 2011. Deficiency of sorting nexin 27 (SNX27) leads to growth retardation and elevated levels of N-methyl-D-aspartate receptor 2C (NR2C). Mol Cell Biol 31:1734-47.

- Carlton J, Bujny M, Rutherford A, Cullen P. 2005. Sorting Nexins - Unifying trends and new perspectives. Traffic 6:75-82.36

- Ceruti S, Vigano F, Boda E, Ferrario S, Magni G, Boccazzi M, Rosa P, Buffo A, Abbracchio MP. 2011. Expression of the new P2Y-like receptor GPR17 during oligodendrocyte precursor cell maturation regulates sensitivity to ATP-induced death. Glia 59:363-378.

- Chen Y, Wu H, Wang S, Koito H, Li J, Ye F, Hoang J, Escobar SS, Gow A, Arnett HA, Trapp BD, Karandikar NJ, Hsieh J, Lu QR. 2009. The oligodendrocyte-specific G protein-coupled receptor GPR17 is a cell-intrinsic timer of myelination. Nature Neurosci 12:1398-1406.

- Chen YJ, Fang PC. 2005. Sensory evoked potentials in infants with Down syndrome. Acta Paediatr 94:1615-1618.

- Ciana P, Fumagalli M, Trincavelli ML, Verderio C, Rosa P, Lecca D, Ferrario S, Parravicini C, Capra V, Gelosa P, Guerrini U, Belcredito S, Cimino M, Sironi L, Tremoli E, Rovati GE, Martini C, Abbracchio MP. 2006. The orphan receptor GPR17 identified as a new dual uracil nucleotides/cysteinyl-leukotrienes receptor. EMBO J 25:4615-4627.

- Contestabile A, Fila T, Ceccarelli C, Bonasoni P, Bonapace L, Santini D, Bartesaghi R, Ciani E. 2007. Cell cycle alteration and decreased cell proliferation in the hippocampal dentate gyrus and in the neocortical germinal matrix of fetuses with Down syndrome and in Ts65Dn mice. Hippocampus 17:665-678.

- Coppi E, Maraula G, Fumagalli M, Failli P, Cellai L, Bonfanti E, Mazzoni L, Coppini R, Abbracchio MP, Pedata F, Pugliese AM. 2013. UDP-glucose enhances outward K(+) currents necessary for cell differentiation and stimulates cell migration by activating the GPR17 receptor in oligodendrocyte precursors. Glia 61:1155-1171.

- Damseh N, Danson CM, Al-Ashhab M, Abu-Libdeh B, Gallon M, Sharma K, Yaacov B, 
Coulthard E, Caldwell MA, Edvardson S, Cullen PJ, Elpeleg O. 2015. A defect in the retromer accessory protein, SNX27, manifests by infantile myoclonic epilepsy and neurodegeneration. Neurogenetic 16:215-221.

- Daniele S, Trincavelli ML, Fumagalli M, Zappelli E, Lecca D, Bonfanti E, Campiglia P, Abbracchio MP, Martini C. 2014. Does GRK- $\beta$ arrestin machinery work as a "switch on" for GPR17-mediated activation of intracellular signaling pathways? Cell Signal 26:1310-1325.

- Dougherty JD, Fomchenko EI, Akuffo AA, Schmidt E, Helmy KY, Bazzoli E, Brennan CW, Holland EC, Milosevic A. 2012. Candidate pathways for promoting differentiation or quiescence of oligodendrocyte progenitor-like cells in glioma. Cancer Res 72:4856-4868.

- Fam SR, Paquet M, Castleberry AM, Oller H, Lee CJ, Traynelis SF, Smith Y, Yun CC, Hall RA. 2005. P2Y1 receptor signaling is controlled by interaction with the PDZ scaffold NHERF-2. Proc Natl Acad Sci U S A 102:8042-8047.

- Fields RD. 2008. White matter in learning, cognition and psychiatric disorders. Trends Neurosci. 31:361-70.

- Fratangeli A, Parmigiani E, Fumagalli M, Lecca D, Benfante R, Passafaro M, Buffo A, Abbracchio MP, Rosa P. 2013. The regulated expression, intracellular trafficking and membrane recycling of the P2Y-like receptor GPR17 in Oli-neu oligodendroglial cells. J Biol Chem 288:5241-5256.

- Fumagalli M, Daniele S, Lecca D, Lee PR, Parravicini C, Fields RD, Rosa P, Antonucci F, Verderio C, Trincavelli ML, Bramanti P, Martini C, Abbracchio MP. 2011. Phenotypic changes, signaling pathway, and functional correlates of GPR17-expressing neural precursor cells during oligodendrocyte differentiation. J Biol Chem 286:10593-10604.

- Fumagalli M, Bonfanti E, Daniele S, Zappelli E, Lecca D, Martini C, Trincavelli ML, Abbracchio MP. 2015. The ubiquitin ligase Mdm2 controls oligodendrocyte maturation by interwining mTor with G protein-coupled receptor kinase 2 in the regulation of GPR17 receptor desensitization. Glia 63:2327-2339.

- Gallon M, Clairfeuille T, Steinberg F, Mas C, Ghai R, Sessions RB, Teasdale RD, Collins BM, Cullen PJ. 2014. A unique PDZ domain and arrestin-like fold interaction reveals mechanistic details of endocytic recycling by SNX27-retromer. Proc Natl Acad Sci U S A 111:E3604-E3613.

- Grandy D, Shan J, Zhang X, Rao S, Akunuru S, Li H, Zhang Y, Alpatov I, Zhang XA, Lang RA, Shi DL, Zheng JJ. 2009. Discovery and characterization of a small molecule inhibitor of the PDZ domain of dishevelled. J Biol Chem 284:16256-16263.

- Guidi S, Bonasoni P, Ceccarelli C, Santini D, Gualtieri F, Ciani E, Bartesaghi R. 2008. Neurogenesis impairment and increased cell death reduce total neuron number in the hippocampal region of fetuses with Down syndrome. Brain Pathology 18:180-197.

- Guidi S, Ciani E, Bonasoni P, Santini D, Bartesaghi R. 2011. Widespread proliferation impairment and hypocellularity in the cerebellum of fetuses with Down syndrome. Brain Pathology 21:361-373.

- Guidi S, Stagni F, Bianchi P, Ciani E, Giacomini A, De Franceschi M, Moldrich R, Kurniawan N, Mardon K, Giuliani A, Calzà L, Bartesaghi R. 2014. Prenatal pharmacotherapy rescues brain 
development in a Down's syndrome mouse model. Brain 137:380-401.

- Haydar TF, Nowakowski RS, Yarowsky PJ, Krueger BK. 2000. Role of founder cell deficit and delayed neuronogenesis in microencephaly of the trisomy 16 mouse. J Neurosci 20:4156-4164.

- Heath M, Grierson L, Binsted G, Elliott D. 2007. Interhemispheric transmission time in persons with Down syndrome. J Intellect Disabil Res 51:972-981.

- Hennen S, Wang H, Peters L, Merten N, Simon K, Spinrath A, Blättermann S, Akkari R, Schrage R, Schröder R, Schulz D, Vermeiren C, Zimmermann K, Kehraus S, Drewke C, Pfeifer A, König GM, Mohr K, Gillard M, Müller CE, Lu QR, Gomeza J, Kostenis E. 2013. Decoding signaling and function of the orphan G protein-coupled receptor GPR17 with a small-molecule agonist. Sci Signal 6:1-16.

- Hossain S, Liu HN, Fragoso G, Almazan G. 2014. Agonist-induced down-regulation of AMPA receptors in oligodendrocyte progenitors. Neuropharmacology 79:506-514.

- Hu F, Padukkavidana T, Vægter CB, Brady OA, Zheng Y, Mackenzie IR, Feldman HH, Nykjaer A, Strittmatter SM. 2010. Sortilin-mediated endocytosis determines levels of the frontotemporal dementia protein, progranulin. Neuron 68:654-667.

- Hussain NK, Diering GH, Sole J, Anggono V, Huganir RL. 2014. Sorting Nexin 27 regulates basal and activity-dependent trafficking of AMPARs. Proc Natl Acad Sci U S A 111:1184011845.

- Joubert L, Hanson B, Barthet G, Sebben M, Claeysen S, Hong W, Marin P, Dumuis A, Bockaert J. 2004. New sorting nexin (SNX27) and NHERF specifically interact with the 5-HT4(a) receptor splice variant: roles in receptor targeting. J Cell Sci 117:5367-5379.

- Jung M, Krämer E, Grzenkowski M, Tang K, Blakemore W, Aguzzi A, Khazaie K, Chlichlia K, von Blankenfeld G, Kettenmann H. 1995. Lines of murine oligodendroglial precursor cells immortalized by an activated neu tyrosine kinase show distinct degrees of interaction with axons in vitro and in vivo. Eur J Neurosci 7:1245-1265.

- Kalay E, de Brouwer AP, Caylan R, Nabuurs SB, Wollnik B, Karaguzel A, Heister JG, Erdol H, Cremers FP, Cremers CW, Brunner HG, Kremer H. 2005. A novel D458V mutation in the SANS PDZ binding motif causes atypical Usher syndrome. J Mol Med 83:1025-1032.

- Lauffer BE, Melero C, Temkin P, Lei C, Hong W, Kortemme T, von Zastrow M. 2010. SNX27 mediates PDZ-directed sorting from endosomes to the plasma membrane. J Cell Biol 190:565574.

- Le TL, Yap AS, Stow JL. 1999. Recycling of E-cadherin: a potential mechanism for regulating cadherin dynamics. J Cell Biol 146:219-232.

- Lecca D, Trincavelli ML, Gelosa P, Sironi L, Ciana P, Fumagalli M, Villa G, Verderio C, Grumelli C, Guerrini U, Tremoli E, Rosa P, Cuboni S, Martini C, Buffo A, Cimino M, Abbracchio MP. 2008. The recently identified P2Y-like receptor GPR17 is a sensor of brain damage and a new target for brain repair. PlosOne 3:e3579.

- Lee HJ, Zheng JJ. 2010. PDZ domain and their binding partners: structure, specificity, and modification. Cell Commun Signal 8:8.

- Lee SS, Weiss RS, Javier RT. 1997. Binding of human virus oncoproteins to hDlg/SAP97, a 
mammalian homolog of the Drosophila discs large tumor suppressor protein. Proc Natl Acad Sci USA 94:6670-6675.

- $\quad$ Li C, Xiao L, Liu X, Yang W, Shen W, Hu C, Yang G, He C. 2013. A functional role of NMDA receptor in regulating the differentiation of oligodendrocyte precursor cells and remyelination. Glia 61:5732-5749.

- Linetti A, Fratangeli A, Taverna E, Valnegri P, Francolini M, Cappello V, Matteoli M, Passafaro M, Rosa P. 2010. Cholesterol reduction impairs exocytosis of synaptic vesicles. J Cell Sci 123:595- 605.

- Liu DP, Schmidt C, Billings T, Davisson MT. 2003. Quantitative PCR genotyping assay for the Ts65Dn mouse model of Down syndrome. Biotechniques 35:1170-1174.

- Loo LS, Tang N, Al-Haddawi M, Dawe GS, Hong W. 2014. A role for sorting nexin 27 in AMPA receptor trafficking. Nat Commun 5:3176.

- Luo F, Burke K, Kantor C, Miller RH, Yang Y. 2014. Cyclin-dependent kinase 5 mediates adult OPC maturation and myelin repair through modulation of Akt and GsK-3 $\beta$ signaling. J Neurosci 34:10415-10429.

- Lunn ML, Nassirpour R, Arrabit C, Tan J, McLeod I, Arais CM, Sawchenko PE, Yates JR 3rd, Slesinger PA. 2007. A unique sorting nexin regulates trafficking of potassium channels via PDZ domain interaction. Nature Neurosci 10:1249-1259.

- Mao FX, Li WJ, Chen HJ, Qian LH, Buzby JS. 2012. Periventricular leukomalacia long-term prognosis may be improved by treatment with UDP-glucose, GDNF, and memantine in neonatal rats. Brain Res 1486:112-120.

- McGough IJ, Steinberg F, Gallon M, Yatsu A, Ohbayashi N, Heesom KJ, Fukuda M, Cullen PJ. 2014. Identification of molecular heterogeneity in SNX27-retromer-mediated endosome-toplasma- membrane recycling. J Cell Sci 127:4940-4953.

- Medina-Rodriguez E, Arenzana FJ, Bribian A, de Castro F. 2013. Protocol to isolate a large amount of functional oligodendrocyte precursor cells from the cerebral cortex of adult mice and humans PLoS One 8:e81620.

- Mejias R, Adamczyk A, Anggono V, Niranjan T, Thomas GM, Sharma K, Skinner C, Schwartz CE, Stevenson RE, Fallin MD, Kaufmann W, Pletnikov M, Valle D, Huganir RL, Wang T. 2011. Gain- of-function glutamate receptor interacting protein 1 variants alter GluA2 recycling and surface distribution in patients with autism. Proc Natl Acad Sci U S A 108:4920-4925.

- Mitew S, Hay CM, Peckham H, Xiao J, Koenning M, Emery B. 2014. Mechanisms regulating the development of oligodendrocytes and central nervous system myelin. Neurosci 276:29-47.

- Munoz MB, Slesinger PA. 2014. Sorting nexin 27 regulation of G protein-gated inwardly rectifying $\mathrm{K}+$ channels attenuates in vivo cocaine response. Neuron 82:659-669.

- Niethammer M, Kim E, Sheng M. 1996. Interaction between the C terminus of NMDA receptor subunits and multiple members of the PSD-95 family of membrane-associated guanylate kinases. J Neurosci 16:2157-2163.

- Nisar SP, Cunningham M, Saxena K, Pope RJ, Kelly E, Mundell SJ. 2012. Arrestin scaffolds NHERF1 to the P2Y12 receptor to regulate receptor internalization. J Biol Chem 287:24505- 
24015.

- Piddini E, Marshall F, Dubois L, Hirst E, Vincent JP. 2005. Arrow (LRP6) and Frizzled2 cooperate to degrade Wingless in Drosophila imaginal discs. Development 132:5479-5489.

- Reczek D, Berryman M, Bretscher A. 1997. Identification of EBP50 a PDZ-containing phosphoprotein that associates with members of the ezrin-radixin-moesin family. $\mathrm{J}$ Cell Biol 139:169-179.

- Reeves RH, Irving NG, Moran TH, Wohn A, Kitt C, Sisodia SS, Schmidt C, Bronson RT, Davisson MT. 1995. A mouse model for Down syndrome exhibits learning and behaviour deficits. Nat Genet 11:177-184.

- Rives AF, Rochlin KM, Wehrli M, Schwartz SL, Di Nardo S. 2006. Endocytic trafficking of Wingless and its receptors, Arrow and DFrizzled-2, in the Drosophila wing. Dev Biol 293:268683.

- Sachs HH, Bercury KK, Popescu DC, Narayanan SP, Macklin WB. 2014. A new model of cuprizone-mediated demyelination/remyelination. ASN Neuro 6:1759091414551955.

- Seto ES, Bellen HJ. 2006. Internalization is required for proper Wingless signaling in Drosophila melanogaster. J Cell Biol 173:95-106.

- Simons M, Lyons DA. 2013. Axonal selection and myelin sheath generation in the central nervous system. Curr Opin Cell Biol 25:512-519.

- Singh V, Yang J, Cha B, Chen TE, Sarker R, Yin J, Avula LR, Tse M, Donowitz M. 2015. Sorting nexin 27 regulates basal and stimulated brush border trafficking of NHE3. Mol Biol Cell 26:20302043.

- Small SA, Kent K, Pierce A, Leung C, Kang MS, Okada H, Honig L, Vonsattel JP, Kim TW. 2005. Model-guided microarray implicates the retromer complex in Alzheimer's disease. Ann Neurol 58:909-919.

- Songyang Z, Fanning AS, Fu C, Xu J, Marfatia SM, Chishti AH, Crompton A, Chan AC, Anderson JM, Cantley LC. 1997. Recognition of unique carboxyl-terminal motifs by distinct PDZ domains. Science 275:73-77.

- Steinberg F, Gallon M, Winfield M, Thomas EC, Bell AJ, Heesom KJ, Tavaré JM, Cullen PJ. 2013. A global analysis of SNX27-retromer assembly and cargo specificity reveals a function in glucose and metal ion transport. Nat Cell Biol 15:461-471.

- Stevens B, Porta S, Haak LL, Gallo V, Fields RD. 2002. Adenosine: a neuron-glial transmitter promoting myelination in the CNS in response to action potentials. Neuron 36:855-868.

- Temkin P, Lauffer B, Jäger S, Cimermancic P, Krogan NJ, von Zastrow M. 2011. SNX27 mediates retromer tubule entry and endosome-to-plasma membrane trafficking of signalling receptors. Nat Cell Biol 13:715-721.

- Terawaki S, Maesaki R, Hakoshima T. 2006. Structural basis for NHERF recognition by ERM proteins. Structure 14:777-789.

- Tyler WA, Jain MR, Cifelli SE, Li Q, Ku L, Feng Y, Li H, Wood TL. 2011. Proteomic identification of novel targets regulated by the mammalian target of rapamycin pathway during oligodendrocyte differentiation. Glia 59:1754-1769. 
- Viganò F, Schneider S, Cimino M, Bonfanti E, Gelosa P, Sironi L, Abbracchio MP, Dimou L. 2016. GPR17 expressing NG2-Glia: Oligodendrocyte progenitors serving as a reserve pool after injury. Glia 64:287-299.

- Vilariño-Güell C, Wider C, Ross OA, Dachsel JC, Kachergus JM, Lincoln SJ, Soto-Ortolaza AI, Cobb SA, Wilhoite GJ, Bacon JA, Behrouz B, Melrose HL, Hentati E, Puschmann A, Evans DM, Conibear E, Wasserman WW, Aasly JO, Burkhard PR, Djaldetti R, Ghika J, Hentati F, Krygowska- Wajs A, Lynch T, Melamed E, Rajput A, Rajput AH, Solida A, Wu RM, Uitti RJ, Wszolek ZK, Vingerhoets F, Farrer MJ. 2011. VPS35 mutations in Parkinson disease. Am J Hum Genet 89:162- 167.

- Wake H, Lee PR, Fields RD. 2011. Control of local protein synthesis and initial events in myelination by action potentials. Science 333:1647-1651.

- Walrafen P, Verdier F, Kadri Z, Chrétion S, Lacombe C, Mayeux P. 2005. Both proteasomes and lysosomes degrade the activated erythropoietin receptor. Blood 15:600-608.

- Wang X, Zhao Y, Zhang X, Badie H, Zhou Y, Mu Y, Loo LS, Cai L, Thompson RC, Yang B, Chen Y, Johnson PF, Wu C, Bu G, Mobley WC, Zhang D, Gage FH, Ranscht B, Zhang YW, Lipton SA, Hong W, Xu H. 2013. Loss of sorting nexin 27 contributes to excitatory synaptic dysfunction by modulating glutamate receptor recycling in Down's syndrome. Nature Medicine 19:473-481.

- Wang X, Huang T, Zhao Y, Zheng Q, Thompson RC, Bu G, Zhang YW, Hong W, Xu H. 2014. Sorting nexin 27 regulates $A \circledast$ production through modulating $\odot$-secretase activity. Cell Reports 9:1023-1033.

- Winterstein C, Trotter J, Krämer-Albers EM. 2008. Distinct endocytic recycling of myelin proteins promotes oligodendroglial membrane remodeling. J Cell Sci 121:834-842.

- Yu A, Rual JF, Tamai K, Harada Y, Vidal M, He X, Kirchhausen T. 2007. Association of Dishevelled with the clathrin AP-2 adaptor is required for Frizzled endocytosis and planar cell polarity signaling. Dev Cell 12:129-141.

- Zimprich A, Benet-Pagès A, Struhal W, Graf E, Eck SH, Offman MN, Haubenberger D, Spielberger S, Schulte EC, Lichtner P, Rossle SC, Klopp N, Wolf E, Seppi K, Pirker W, Presslauer S, Mollenhauer B, Katzenschlager R, Foki T, Hotzy C, Reinthaler E, Harutyunyan A, Kralovics R, Peters A, Zimprich F, Brücke T, Poewe W, Auff E, Trenkwalder C, Rost B, Ransmayr G, Winkelmann J, Meitinger T, Strom TM. 2011. A mutation in VPS35, encoding a subunit of the retromer complex, causes late-onset Parkinson disease. Am J Hum Genet 89:168175 . 


\section{FIGURE LEGENDS}

\section{Figure 1. GPR17 with a PDZ binding motif mutation is mis-sorted.}

Representative immunofluorescence micrographs showing HEK293 cells transfected with mGPR17-WT (WT, a-b") or mGPR17-SELA (SELA, c-d”). To label receptors exposed to the cell surface and track their fate, cells were incubated at $37^{\circ} \mathrm{C}$ with the $\langle\mathrm{Nt}-\mathrm{GPR} 17$ antibody before fixation, and double-labeled with anti-rabbit IgG conjugated to Cy3 to reveal GPR17 (a', b', c', d') and monoclonal anti-cadherin antibody (Cadh, a", c") or transferrin receptor (TfR, b", d") to stain plasma membrane and endocytic vesicles, respectively. Merged images are shown in a, b, c, d. While mGPR17-WT is mainly expressed on the cell surface (arrows in a-a"), mGPR17-SELA is internalized in vesicles and partially colocalizes with TfR, a marker of recycling endosomes (arrows in d-d"). Scale Bars: 10 (m.

\section{Figure 2. mGPR17-SELA is retained intracellularly after internalization.}

A, E Representative immunofluorescence micrographs showing surface GPR17 labeling of HEK293 cells with affinity-purified /Nt-GPR17 after transfection with either mGPR17-WT or mGPR17SELA. B, F Representative immunofluorescence micrographs showing internalization of GPR17-WT or SELA. Upon stimulation with 100 (M UDP-glucose, the cells were washed with glycine buffer ( $\mathrm{pH} 2.8)$ to remove antibodies bound to the remaining cell surface-exposed receptors, and then fixed ( $0 \mathrm{~min})$. C, D, G, H Representative immunofluorescence micrographs showing that more mGPR17-SELA than WT receptors are retained intracellularly following agonist removal for 10 or $20 \mathrm{~min}$. Scale bar: $10 / \mathrm{m}$. I Quantitative analysis of the intensity of GPR17 immunoreactivity detected on the cell surface before stimulation, as determined using ImageJ software. The values are expressed as arbitrary units and represent the mean value \pm s.e.m.; $n=10$ cells transfected with GPR17-WT and 12 cells transfected with GPR17-SELA. L Quantitative analysis of the intensity of GPR17 immunoreactivity in the cells at 0,10 and $20 \mathrm{~min}$ after agonist removal. The data are expressed as the percentage of immunoreactivity detected after agonist-induced internalization (time $0=100 \%)$ and are the mean values \pm s.e.m. detected in $93(0$ min), 79 (10 min), and 104 (20 min) GPR17-WT transfected cells or 113 (0 min), 110 (20 min) and 98 (20 min) GPR17-SELA transfected cells, respectively. *** $\mathrm{P}=0.0007$; ** $\mathrm{P}=0.0051$ (unpaired two-tailed Student's t-test).

\section{Figure 3. The plasma membrane recycling of GPR17-SELA is impaired.}

Representative micrographs recorded before, immediately after UDP-glucose stimulation or 15 min after UDP-glucose removal showing that FLAG-hGPR17-WT is returned to the plasma membrane (arrows) after agonist removal while FLAG-hGPR17-SELA is mainly retained in intracellular dot- like structures (arrow-heads). HEK293 cells expressing FLAG-hGPR17-WT or FLAG-hGPR17- SELA were incubated in vivo with a mouse anti-FLAG antibody (red) before agonist stimulation. DAPI nuclear labeling is shown in blue. Scale bar: $10 \mu \mathrm{m}$.

\section{Figure 4. GPR17 interacts with SNX27 in vitro and is recruited into SNX27-positive endosomes after internalization.}

A Schematic view of peptides corresponding to the C-terminal tail of GPR17 with (CT) or without 
the PDZ-binding motif ( $\triangle \mathrm{CT}$ ) conjugated to Sepharose 4B used in the pull-down experiments. B, C Endogenous SNX27, but not NHERF, is specifically recovered by the PDZ-binding motif of GPR17. CT or $\Delta \mathrm{CT}$ beads $(20 \mu \mathrm{l})$ were incubated with Oli-neu cell lysates $(500 \mu \mathrm{g}$ of proteins). Proteins eluted from the Sepharose matrices and aliquots of total lysates (30 $\mu \mathrm{g}$ of proteins, Lys) were analyzed after being transferred to nitrocellulose filters by Ponceau staining (B) followed by immunolabeling with antibodies against NHERF or SNX27. Blots representative of three independent experiments are shown (C). D, E The PDZ domain of SNX27 directly interacts with the PDZ-binding motif of GPR17. CT or $\Delta$ CT beads $(20 \mu \mathrm{l})$ were incubated with purified His- 49 SNX27 (D) or lysates from BL21DE3 expressing wild-type His-SNX27 (WT) or His-SNX27 harboring a point mutation in the PDZ domain (H/A) (E). Proteins eluted from the Sepharose matrices and aliquots of bacterial lysates were analyzed by Western blotting. In $\mathrm{D}$ and $\mathrm{E}$, blots representative of three independent experiments are shown. F, G Representative immunofluorescence micrographs showing colocalization of SNX27 with endogenous GPR17 after internalization. Oli-neu cells (F) and primary OPC cultures $(\mathrm{G})$ exposed for $48 \mathrm{~h}$ to $\mathrm{CM}$ or neurobasal medium, respectively, to foster cell differentiation and GPR 17 expression, were incubated at $4{ }^{\circ} \mathrm{C}$ with affinity-purified $/ \mathrm{Nt}-\mathrm{rGPR} 17$ antibody and then stimulated with 100 (M UDP-glucose. Ten minutes after agonist removal, the cells were washed with glycine, to remove labeling from plasma membrane receptors, fixed and double-immunostained with an anti-rabbit IgG conjugated to Cy3 to detect GPR17, and a goat polyclonal antibody against SNX27 revealed by staining with an anti-goat biotin-conjugated IgG antibody followed by streptavidin-fluorescein. Merged images are shown in F, f and G, g. Note that GPR17 partially colocalizes with SNX27 in vesicles scattered in the cytoplasm (arrows in f-f”, g-g”). Scale bars: $\mathrm{F}$ and $\mathrm{G}=5 \mu \mathrm{m}$; f-g" $=1 \mu \mathrm{m}$.

\section{Figure 5. SNX27 knock-down affects the stability of GPR17.}

A Oli-neu cells were transfected with either shRNA-Scr or shRNA-SNX27 vectors carrying GFP. After $24 \mathrm{~h}$, cells were shifted to CM and incubated for additional $48 \mathrm{~h}$ in order to obtain significant silencing of SNX27, to concomitantly allow cell differentiation and to promote the endogenous expression of GPR17. Equal amounts $(40 \mu \mathrm{g})$ of cell lysates were analyzed by Western blotting. Blots representative of three independent experiments are shown. For quantitative analysis, the signal intensity of the different proteins was standardized to the signal intensity of actin and expressed as a percentage of the amount of protein detected in shRNA-Scr samples (control, set to 100\%). Mean values \pm s.e.m., $n$ $=3 ; * \mathrm{P}=0.011, * * \mathrm{P}=0.0042$ (unpaired two-tailed Student's t-test). B Analysis of GPR17 degradation after addition of the lysosomal inhibitor $\mathrm{NH}_{4} \mathrm{Cl}$ in Oli-neu cells expressing shRNA-Scr or shRNA-SNX27. Cells were pre-incubated for $1 \mathrm{~h}$ with cycloheximide $(500 \mu \mathrm{M})$ and $30 \mathrm{~min}$ with UDP-glucose $(100 \mu \mathrm{M})$, followed by $30 \mathrm{~min}$ of recycling in the presence $(+)$ or absence $(-)$ of $\mathrm{NH} 4 \mathrm{Cl}(20 \mathrm{mM})$. Mean values \pm s.e.m., $\mathrm{n}=3$ are indicated; $\mathrm{P}$ values were calculated using one-way ANOVA with the Tukey test: $* \mathrm{P}<0.05 ; * * * \mathrm{P}<0.001$.

\section{Figure 6. SNX27 knock-down impairs the plasma membrane recycling of GPR17.}

Representative immunofluorescence micrographs showing Oli-neu cells co-transfected with plasmids encoding for FLAG-hGPR17 and shRNA-Scr (a-c'') or shRNA-SNX27 (d-f' '). Cells were 
fixed after labeling at $4^{\circ} \mathrm{C}$ with the anti-FLAG antibody (a-a', d-d' '), and after subsequent incubation with UDP-glucose followed by glycine washing (UDP-Gluc stim, time $0 \mathrm{~min}$; b-b', e- e',), or after agonist removal (UDP-Gluc removal, time $10 \mathrm{~min}$; c-c', f-f' '). Cells were then double-immunolabeled with anti-mouse IgG conjugated to $\mathrm{Cy} 3$ to detect FLAG-hGPR17, and with an antibody against NG2 to decorate plasma membranes. FLAG-hGPR17 recycled to the plasma membrane in shRNA-Scrtransfected cells (arrows in c-c') whereas receptor recycling is impaired in SNX27-silenced cultures. Cells with similar GFP intensity were acquired and subjected to quantitative analysis (see Fig. 7). Scale bar $=10 \mu \mathrm{m}$.

\section{Figure 7. Quantitative analysis of GPR17 plasma membrane recycling in shRNA-Scr- or shRNA- SNX27-transfected cells.}

The intensity of anti-FLAG immunoreactivity (corresponding to GPR17 receptor, see Fig. 6) in the cytoplasm and on the plasma membrane of transfected Oli-neu cells was determined immediately after internalization (time 0 min after UDP-Gluc removal) or 10 min after agonist removal using ImageJ software. Data are expressed as the percentage of total immunoreactivity (i.e., plasma membrane plus intracellular staining set to $100 \%$ ) at each selected time points and are the mean \pm s.e.m. of 25 to 32 cells analyzed for each condition from two independent experiments $(* * * \mathrm{P}<0.0001$, unpaired two-tailed Student's t-test).

\section{Figure 8. SNX27 knock-down accelerates OL differentiation.}

A Oli-neu cells were transfected with either shRNA-Scr or shRNA-SNX27 vectors carrying GFP. After $24 \mathrm{~h}$, cells were shifted to CM and incubated for additional $48 \mathrm{~h}$ to promote differentiation and endogenous GPR17 expression. Cells were then fixed and double-immunolabeled with antibodies against GPR17 and myelin proteins. Representative immunofluorescence micrographs showing that after differentiation shRNA-Scr-transfected Oli-neu cells (GFP-positive cells in a and b) express high levels of GPR17 (a', b'), and no myelin proteins (a', b'). Conversely, shRNA- SNX27-transfected cells (GFPpositive cells in c and d) show high immunoreactivity for MAG (c') and MBP (d'), with a concomitant GPR17 down-regulation (c', d'"). B Quantitative analysis (see Materials and Methods for details on image acquisition and analysis) demonstrated that the percentage of $\mathrm{MBP}^{+}$cells was significantly higher in shRNA-SNX27-transfected Oli-neu cells compared with shRNA-Scr-transfected cells. Mean values \pm s.e.m., $n=505$ cells transfected with shRNA-Scr and 523 cells transfected with shRNA-SNX27 were examined. **P=0.0050 (two-tailed Student's t-test). C Representative Western blot of cell lysates (30 $\mu \mathrm{g}$ of proteins) confirmed increased MAG expression in Oli-neu cells transfected with shRNA-SNX27. Histogram on the right shows the quantitative analysis of MAG expression; values are the mean \pm s.e.m., $\mathrm{n}=3 * \mathrm{P}=0.042$ (two-tailed unpaired Student's t-test). D SNX27 knock-down accelerates the downregulation of GPR17 in differentiating OPCs. Mouse OPCs were transfected with shRNA-Scr or shRNASNX27 and then analyzed by Western blotting. Quantitative analysis of Western blots revealed a significant decrease in GPR17 in cultures after SNX27 silencing (mean values \pm s.e.m., $\mathrm{n}=3$, $* \mathrm{P}=0.012$ by two-tailed unpaired Student's t-test). Moreover, an increased number of MAG-expressing cells was detected in OPC cultures transfected with shRNA-SNX27 (mean values \pm s.e.m., $\mathrm{n}=1170$ cells transfected with shRNA-Scr and 1226 cells transfected with shRNA-SNX27; P=0.054 by two-tailed 
unpaired Student's t-test). E Cytoplasmic (Cyto) and nuclear (Nucl) fractions were prepared from transfected Oli-neu cells after $48 \mathrm{~h}$ in CM. Equal amounts of proteins (40 $\mu \mathrm{g}$ ) were subjected to Western blotting analysis for cellular localization of GAPDH, GFP and Id2. After SNX27 silencing, Id2 partially relocalized to the cytoplasmic compartment.

Figure 9. Reduced expression of GPR17 and increased expression of CC1, a marker of mature oligodendrocytes, in the brains of Ts65Dn mice.

A, C Immunohistochemical analysis of the colocalization between Olig2 and GPR17 (A) and Olig2 and CC1 (C) in brain slices from euploid and Ts65Dn mice. Scale bars: $100 \mu \mathrm{m}(\mathrm{A})$ and $50 \mu \mathrm{m}$ (C). B, D Quantification of the number of GPR17- (B) and CC1-positive cells (D) in the whole brain hemisphere (left panels) and in selected brain areas (right panels). The number of cells was normalized to the total number of counted optical fields/condition. The results are the mean \pm s.e.m. of 4 slices in the case of $\mathrm{CC}^{+}$cells, and 10 slices in the case of GPR $17^{+}$cells from 4 animals each for euploid (Eu) and Ts65Dn (Ts) mice. $* \mathrm{P}<0.05$ and $* * \mathrm{P}<0.01$ with respect to the corresponding euploid values by the unpaired two-tailed Student's t-test.

Figure 10. Decreased number of GST $\pi$-positive cells in the brains of Ts65Dn mice.

A Immunohistochemical analysis of GST $\pi$ expression in brain slices from euploid and Ts65Dn mice. Scale bar: 50 (M. B Quantification of the number of GST $\pi$-positive cells in the whole brain hemisphere (left) and in selected brain areas (right). The number of cells was normalized to the total number of counted optical fields/condition. The results are the mean \pm s.e.m. of 4 slices from 3 animals each for euploid (Eu) and Ts65Dn (Ts) mice.

\section{Figure 11. Decreased myelination in brains of Ts65Dn mice.}

A-D' Representative images of brain hemispheres from euploid or Ts65Dn mice immunostained for MBP (see Methods for details on image acquisition and analysis). MBP expression was examined in regions of cortex and dorsal corpus striatum (A, B, C, D; see also Supp. Info. Fig. 8). The selected areas were converted in binary format (A', B', C', D') and the regions between the red lines were subjected to densitometric analysis with the ImageJ program. The mean intensities were quantified in 6 brain slices from 3 animals for each genotype and equal areas for cortex $\left(\right.$ CTX; euploid $=4.95 \mathrm{~mm}^{2}$; Ts65Dn $=5.07$ $\left.\mathrm{mm}^{2}\right)$ or dorsal corpus striatum $\left(\mathrm{STRd}\right.$; euploid $=5.90 \mathrm{~mm}^{2}$; Ts65Dn $=5.90 \mathrm{~mm}^{2}$ ) were examined. Scale bar $=450 \mu \mathrm{m}$. E, F Histograms showing data as \% \pm s.e.m. of euploid set to $100 \%, \mathrm{n}=6 ; * \mathrm{P}<0.05$ with respect to euploid by the unpaired two-tailed Student's t-test. G Western blotting analysis of MBP expression. Left, representative autoradiography of MBP protein expression in hippocampal protein lysates from 3 animals for each genotype. Right, histograms showing the densitometric quantification of the two major isoforms of MBP corresponding to the polypeptides of $14 \mathrm{kDa}$ and 18.5/17 $\mathrm{kDa}$. The results are expressed as $\% \pm$ s.e.m. of euploid set to $100 \%, \mathrm{n}=3 ; * \mathrm{P}<0.05$ with respect to euploid by the unpaired two-tailed Student's t-test. 
Table 1. Primary antibodies used in the study

\begin{tabular}{|c|c|c|}
\hline MAG - monoclonal & Merck Millipore (Billerica, MA) & $\begin{array}{l}\text { Western blotting (dilution } \\
1: 1,000) \text { and immunofluorescence } \\
\text { (dilution } 1: 200 \text { ) }\end{array}$ \\
\hline MBP - monoclonal & Covance (Milan, IT) & $\begin{array}{l}\text { Immunoflourescence (dilution } \\
1: 500 \text { ) }\end{array}$ \\
\hline MBP - monoclonal & Merck Millipore (Temecula, CA) & $\begin{array}{l}\text { Western blotting (dilution } \\
1: 2,000)\end{array}$ \\
\hline FLAG tag-monoclonal & Merck Millipore (Billerica, MA) & $\begin{array}{l}\text { Immunofluorescence of live cells } \\
\text { (dilution } 1: 150 \text { ) and fixed samples } \\
\text { (dilution } 1: 250 \text { ) }\end{array}$ \\
\hline Myc tag-monoclonal & Sigma-Aldrich (Milan, IT) & $\begin{array}{l}\text { Western blotting (dilution 1:500) } \\
\text { and immunofluorescence (dilution } \\
1: 300 \text { ) }\end{array}$ \\
\hline TfR - monoclonal & Life Technologies (Monza, IT) & $\begin{array}{l}\text { Western blotting (dilution } \\
1: 1,000 \text { ) and immunofluorescence } \\
\text { (dilution } 1: 100 \text { ) }\end{array}$ \\
\hline Pan cadherin - monoclonal & Sigma-Aldrich (Milan, IT) & $\begin{array}{l}\text { Western blotting (dilution } \\
1: 1,000) \text { and immunofluorescence } \\
\text { (dilution } 1: 150 \text { ) }\end{array}$ \\
\hline GFP - polyclonal & Merck Millipore (Billerica, MA) & $\begin{array}{l}\text { Western blotting (dilution } \\
1: 2,000) \text { and immunofluorescence } \\
\text { (dilution } 1: 100 \text { ) }\end{array}$ \\
\hline NG2 - monoclonal & Merck Millipore (Billerica, MA) & $\begin{array}{l}\text { Western blotting (dilution } \\
1: 1,000 \text { ) }\end{array}$ \\
\hline NG2 - polyclonal & Merck Millipore (Temecula, CA) & $\begin{array}{l}\text { Immunofluorescence (dilution } \\
1: 150 \text { ) }\end{array}$ \\
\hline NHERF - polyclonal & Thermo Scientific (Rockford, IL) & $\begin{array}{l}\text { Western blotting (dilution } \\
1: 1,000 \text { ), immunofluorescence } \\
\text { (dilution } 1: 100 \text { ) and tyramide } \\
\text { signal amplification staining } \\
\text { (dilution } 1: 10,000 \text { ) }\end{array}$ \\
\hline SNX27 - polyclonal & $\begin{array}{l}\text { Novus Biologicals (Cambridge, } \\
\text { UK) }\end{array}$ & $\begin{array}{l}\text { Western blotting (dilution } \\
1: 1,000) \text { and immunofluorescence } \\
\text { (dilution } 1: 100 \text { ) }\end{array}$ \\
\hline SNX27 - polyclonal & $\begin{array}{l}\text { Raised in goat. Santa Cruz } \\
\text { Biotechnology (Dallas, TX) }\end{array}$ & $\begin{array}{l}\text { Immunofluorescence (dilution } \\
1: 400 \text { ) }\end{array}$ \\
\hline $\begin{array}{l}\text { anti mouse GPR17 C-terminal - } \\
\text { polyclonal }\end{array}$ & $\begin{array}{l}\text { Raised in rabbit (Fratangeli et al., } \\
\text { 2013) }\end{array}$ & $\begin{array}{l}\text { Western blotting (dilution } 1.75 \\
\mu \mathrm{g} / \mu \mathrm{L} \text { ), immunofluorescence, } \\
\text { (dilution } 10 \mu \mathrm{g} / \mu \mathrm{L} \text { ) and } \\
\text { immunohistochemistry (dilution } \\
1: 20,000 \text { ) }\end{array}$ \\
\hline $\begin{array}{l}\text { anti mouse GPR17 N-terminal - } \\
\text { polyclonal }\end{array}$ & $\begin{array}{l}\text { Raised in rabbit (Fratangeli et al., } \\
2013\end{array}$ & $\begin{array}{l}\text { Immunofluorescence of living } \\
\text { cells (dilution } 10 \mu \mathrm{g} / 250 \mu \mathrm{L} \text { ) }\end{array}$ \\
\hline $\begin{array}{l}\text { anti rat GPR17 N-terminal - } \\
\text { polyclonal }\end{array}$ & Raised in rabbit & $\begin{array}{l}\text { Immunofluorescence of living } \\
\text { cells }(10 \mu \mathrm{g} / 250 \mu \mathrm{L})\end{array}$ \\
\hline GS28 - monoclonal & Enzo Life Science (Italy) & $\begin{array}{l}\text { Western blotting (dilution } \\
1: 1,000 \text { ) and immunofluorescence } \\
\text { (dilution } 1: 100 \text { ) }\end{array}$ \\
\hline Actin - monoclonal & Sigma-Aldrich (Milan, IT) & $\begin{array}{l}\text { Western blotting (dilution } \\
1: 1,000)\end{array}$ \\
\hline
\end{tabular}




\begin{tabular}{|c|c|c|}
\hline Olig2-polyclonal & Merck Millipore (Billerica, MA) & $\begin{array}{l}\text { Immunohistochemistry (dilution } \\
1: 200 \text { ) and immunofluorescence } \\
\text { (dilution } 1: 150 \text { ) }\end{array}$ \\
\hline CC1 - monoclonal & Merck Millipore (Billerica, MA) & $\begin{array}{l}\text { Immunohistochemistry (dilution } \\
1: 50 \text { ) }\end{array}$ \\
\hline Id 2 - polyclonal & $\begin{array}{l}\text { Santa Cruz Biotechnology } \\
\text { (Dallas, TX) }\end{array}$ & Western blotting (dilution 1:400) \\
\hline GAPDH - monoclonal & $\begin{array}{l}\text { Santa Cruz Biotechnology } \\
\text { (Dallas, TX) }\end{array}$ & Western blotting (dilution 1:500) \\
\hline GST $\pi-$ polyclonal & Eppendorf(Milan, IT) & $\begin{array}{l}\text { Immunohistochemistry (dilution } \\
1: 500 \text { ) }\end{array}$ \\
\hline mTOR - monoclonal & Cell Signaling (Danvers, MA) & $\begin{array}{l}\text { Western blotting (dilution } \\
1: 1,000)\end{array}$ \\
\hline Phospho-mTOR - monoclonal & Cell Signaling (Danvers, MA) & Western blotting (dilution 1:500) \\
\hline GRK2 - polyclonal & $\begin{array}{l}\text { Santa Cruz Biotechnology } \\
\text { (Dallas, TX) }\end{array}$ & Western blotting (dilution 1:200) \\
\hline$\alpha$-tubulin - monoclonal & Sigma-Aldrich (Milan, IT) & $\begin{array}{l}\text { Western blotting (dilution } \\
1: 1,500)\end{array}$ \\
\hline
\end{tabular}


Table 2. GPR17 C-terminal mutants used in the study

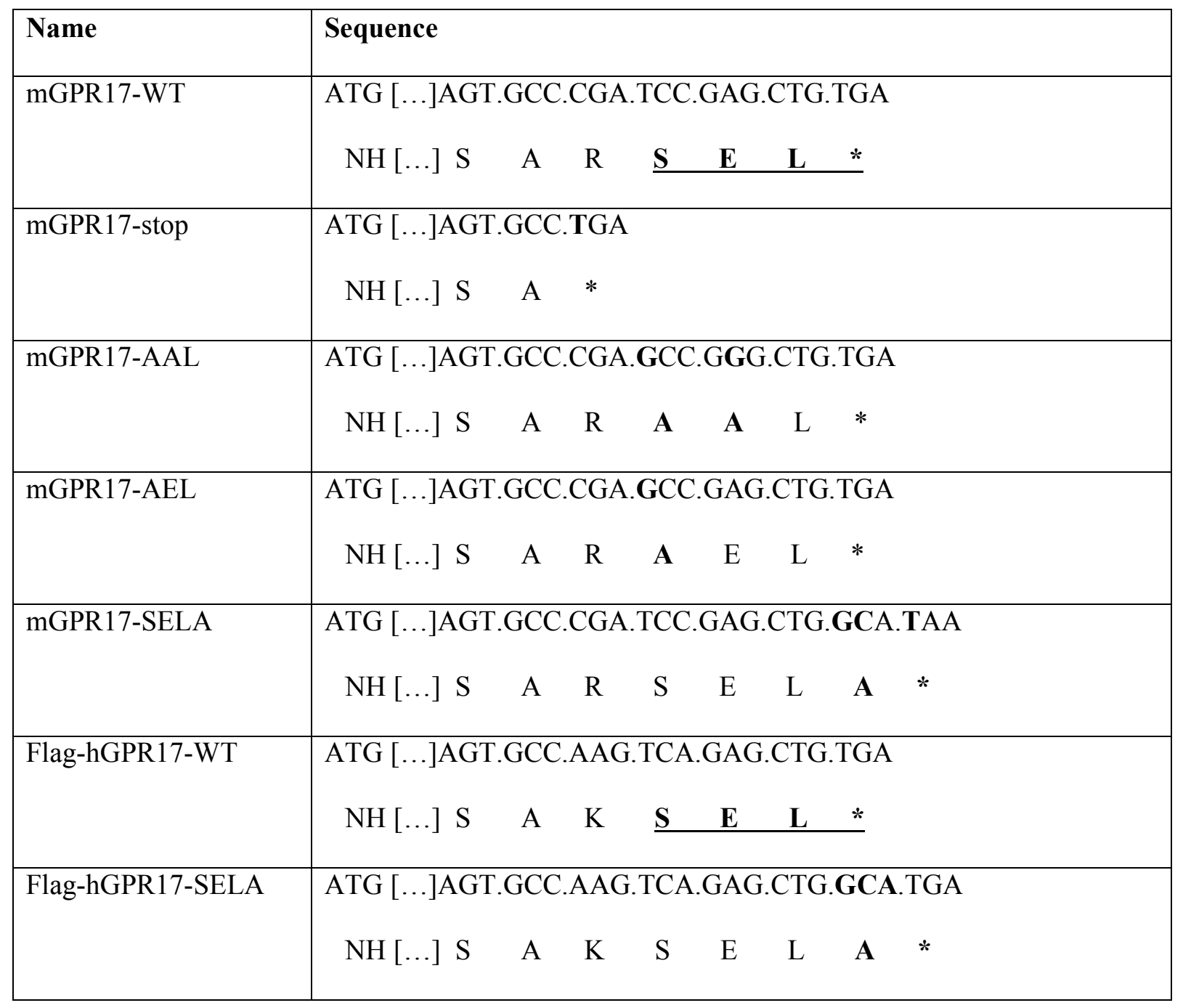

36 

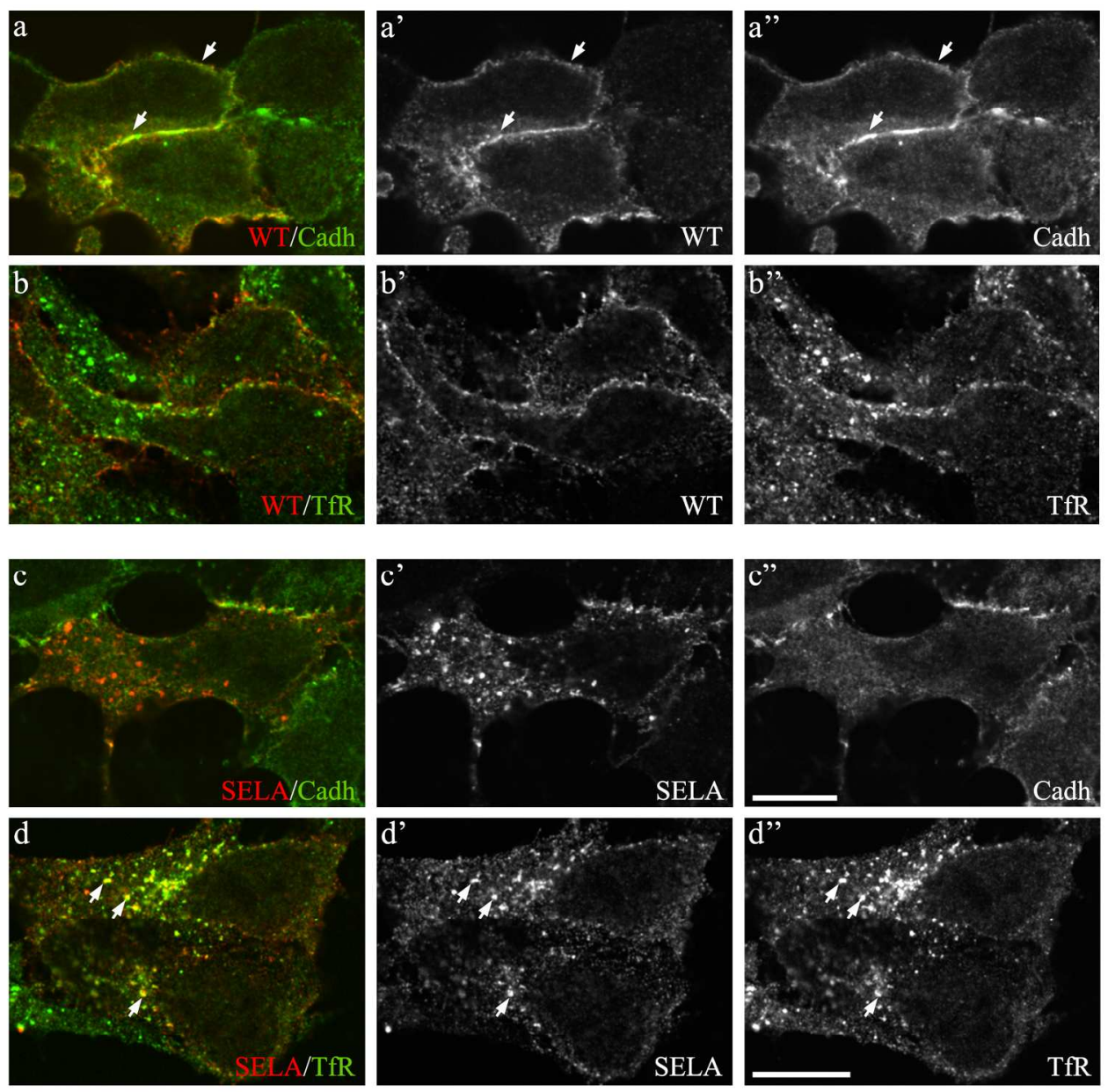

Figure 1. GPR17 with a PDZ binding motif mutation is mis-sorted. 

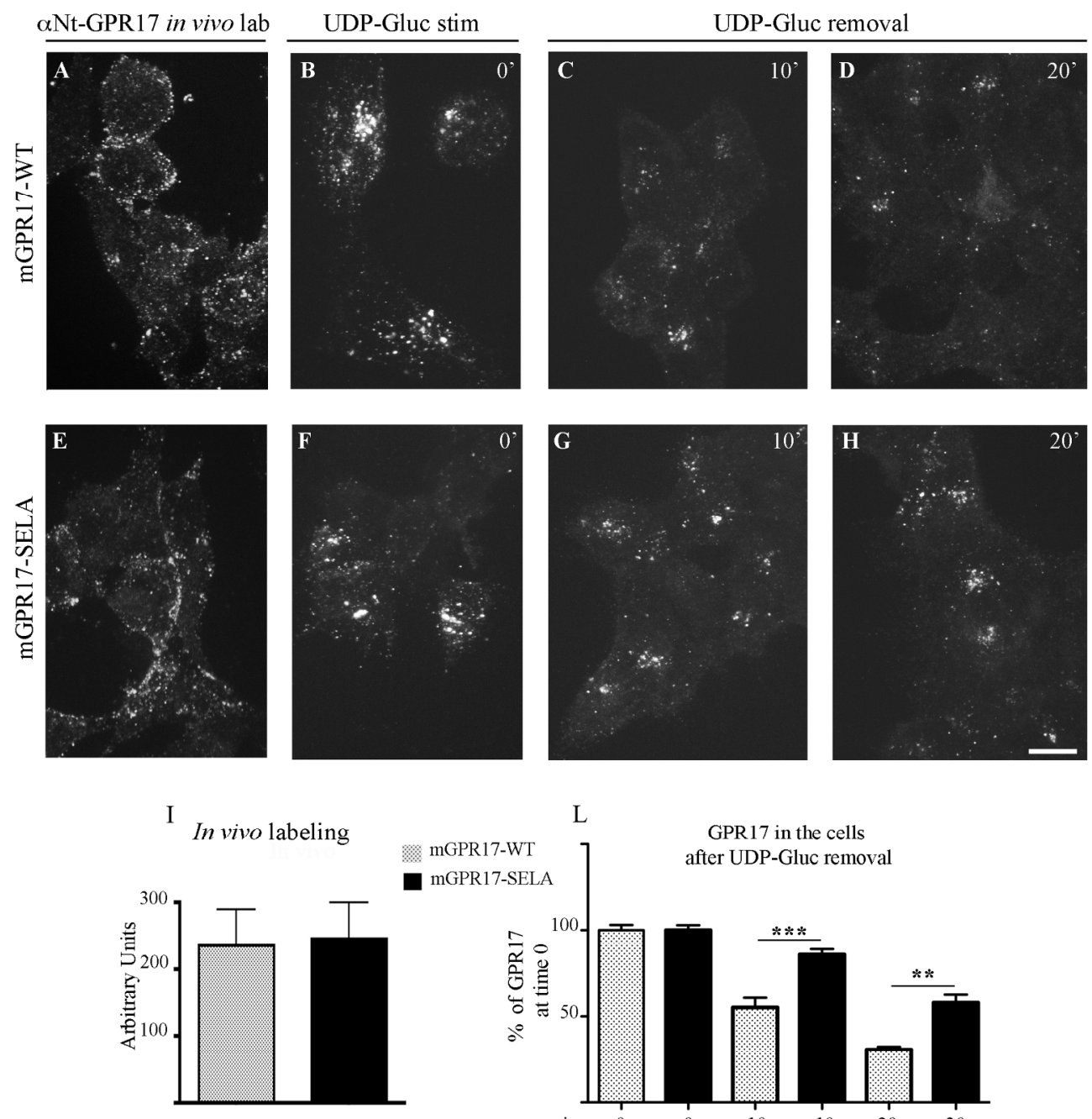

$\mathrm{L}$

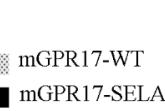

GPR17 in the cells after UDP-Gluc removal

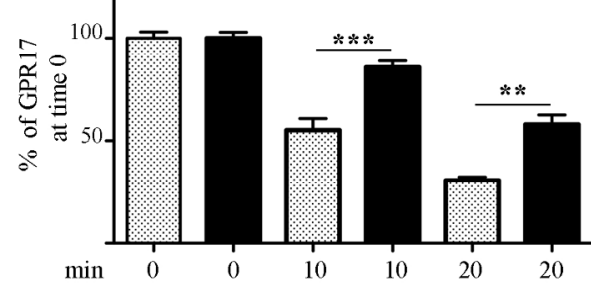

Figure 2. mGPR17-SELA is retained intracellularly after internalization. 


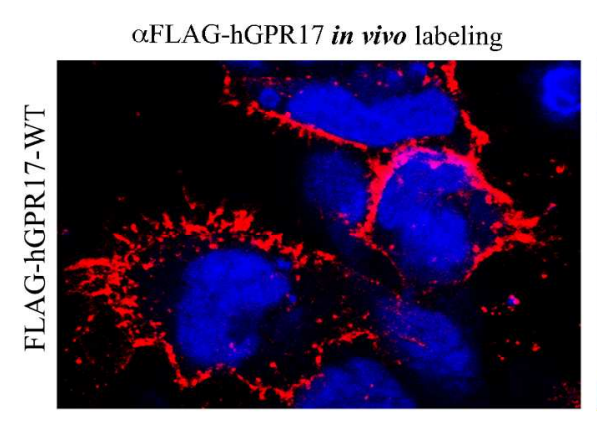

UDP-Gluc stimulation
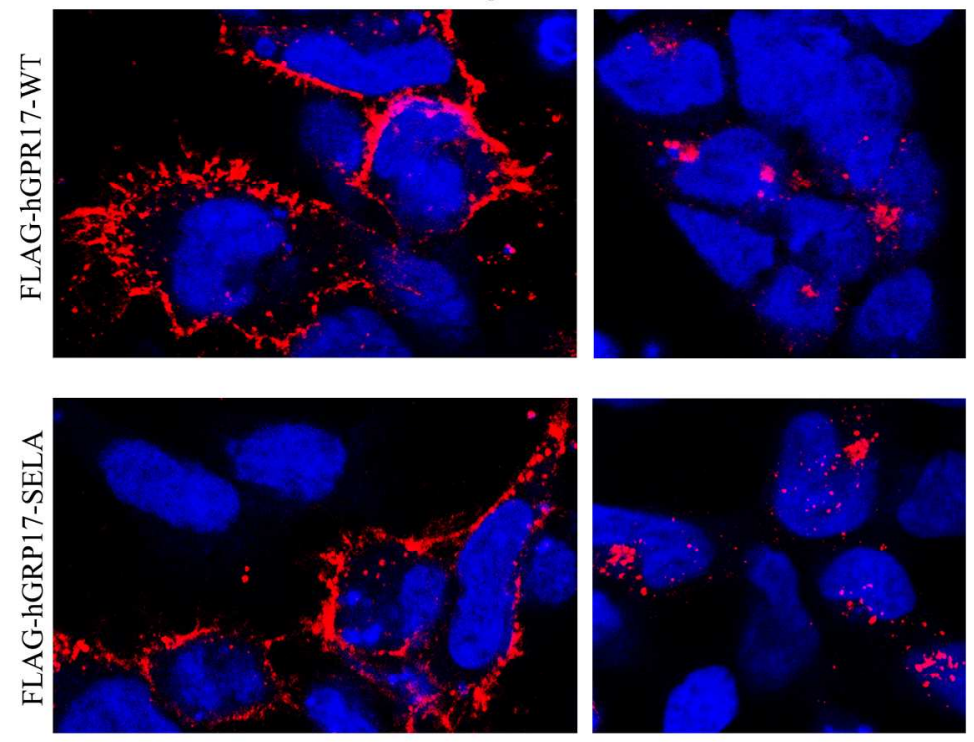

UDP-Gluc removal
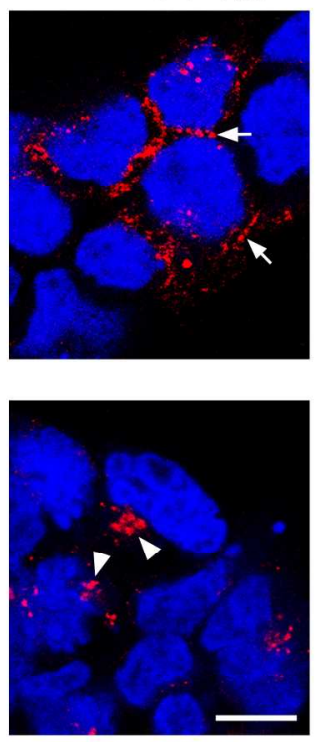

Figure 3. The plasma membrane recycling of GPR17-SELA is impaired. 
A GPR17-CT -SFEGKTNESSLSAKSEL GPR17- $\triangle \mathrm{CT} \bigcirc-S F E G K T N E S S L S A$

B

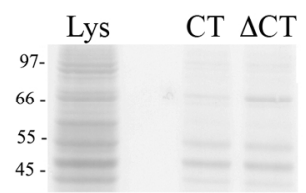

$\mathrm{D}$

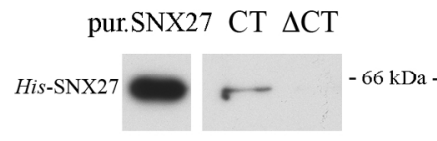

C Oli-neu

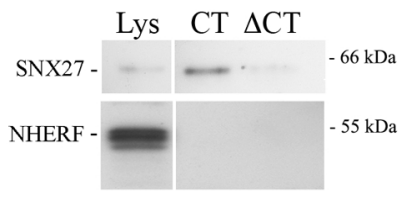

E BL21

Lys $\quad \Delta \mathrm{CT}$

CT
Oli-neu

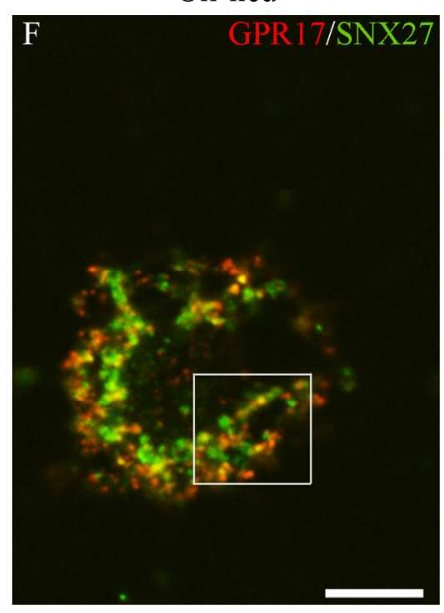

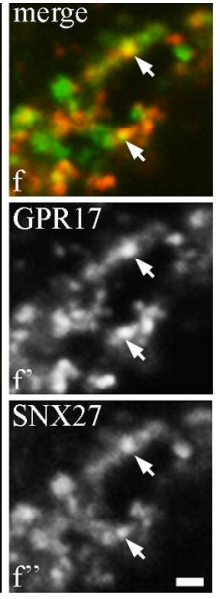

OLs

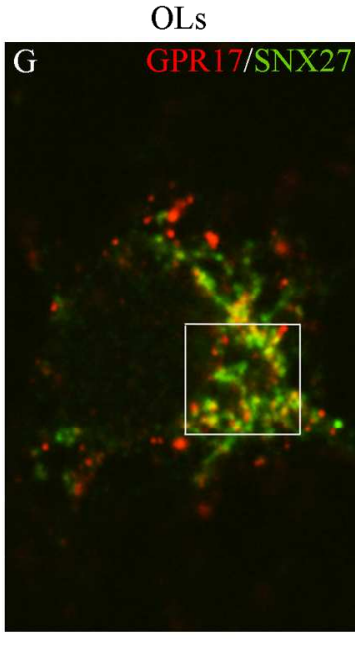

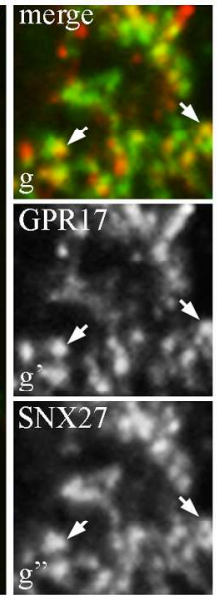

Figure 4. GPR17 interacts with SNX27 in vitro and is recruited into SNX27-positive endosomes after internalization. 


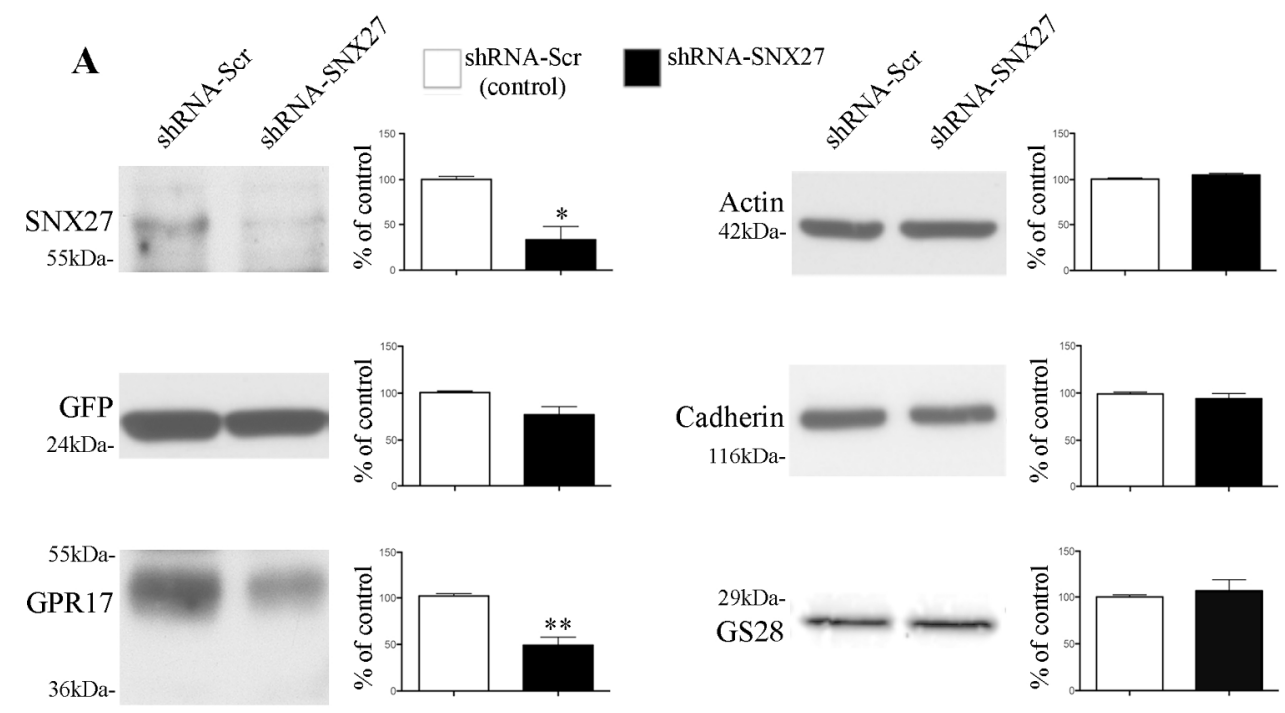

B
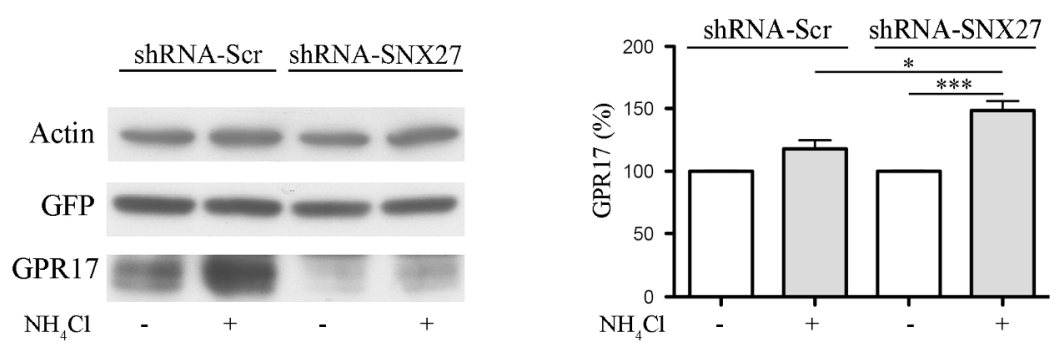

Figure 5. SNX27 knock-down affects the stability of GPR17. 


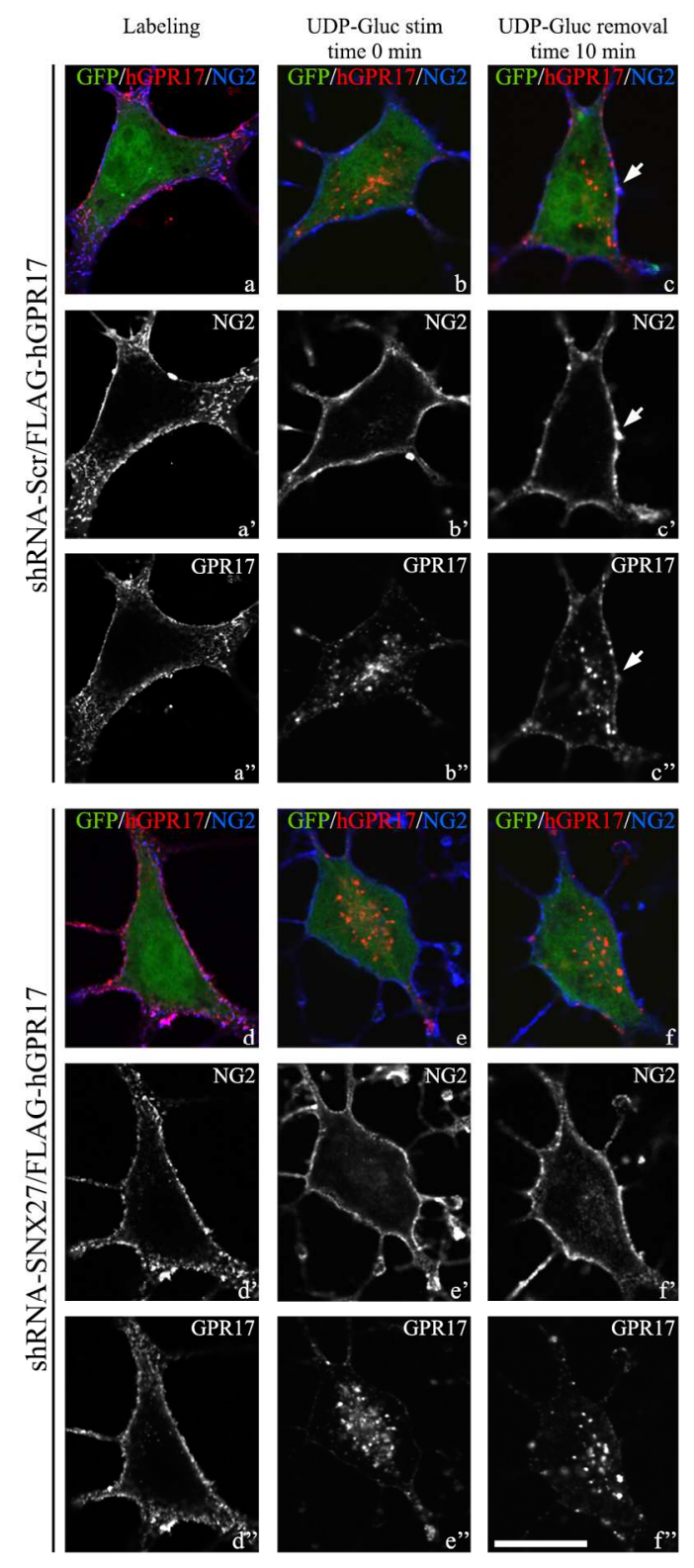

Figure 6. SNX27 knock-down impairs the plasma membrane recycling of GPR17. 
hGPR17/intracellular $]$ hGPR17/membrane $]$ shRA-Scr

$\left.\begin{array}{l}\text { hGPR17/intracellular } \\ \text { hGPR17/membrane }\end{array}\right]$ shRNA-SNX27

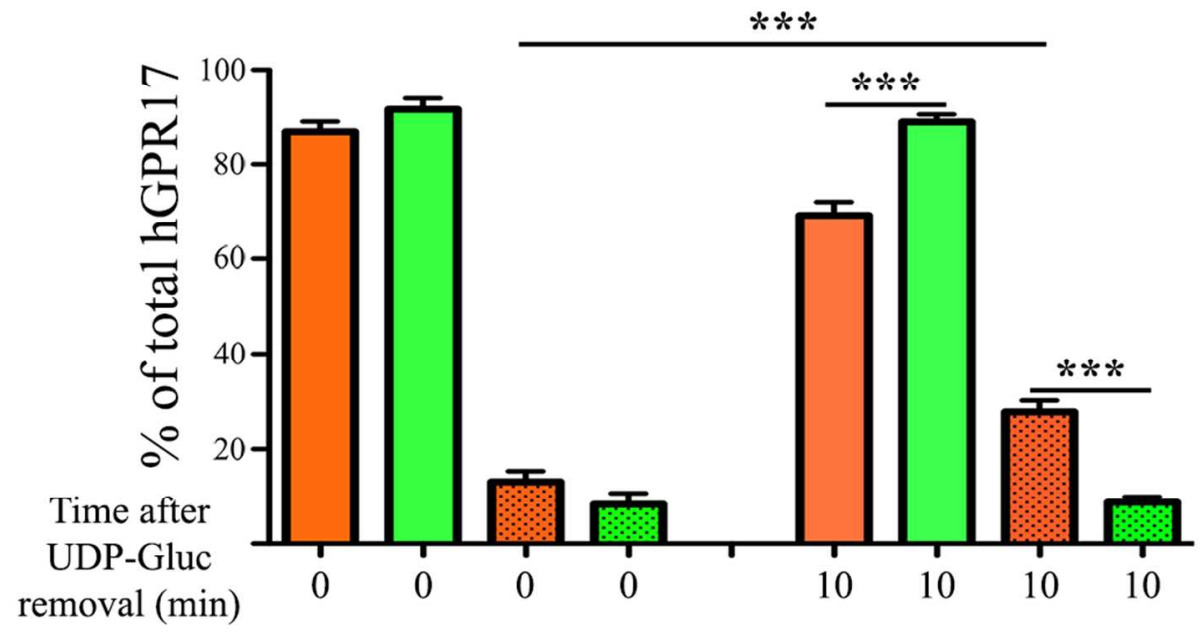

Figure 7. Quantitative analysis of GPR17 plasma membrane recycling in shRNA-Scr- or shRNA-SNX27transfected cells. 

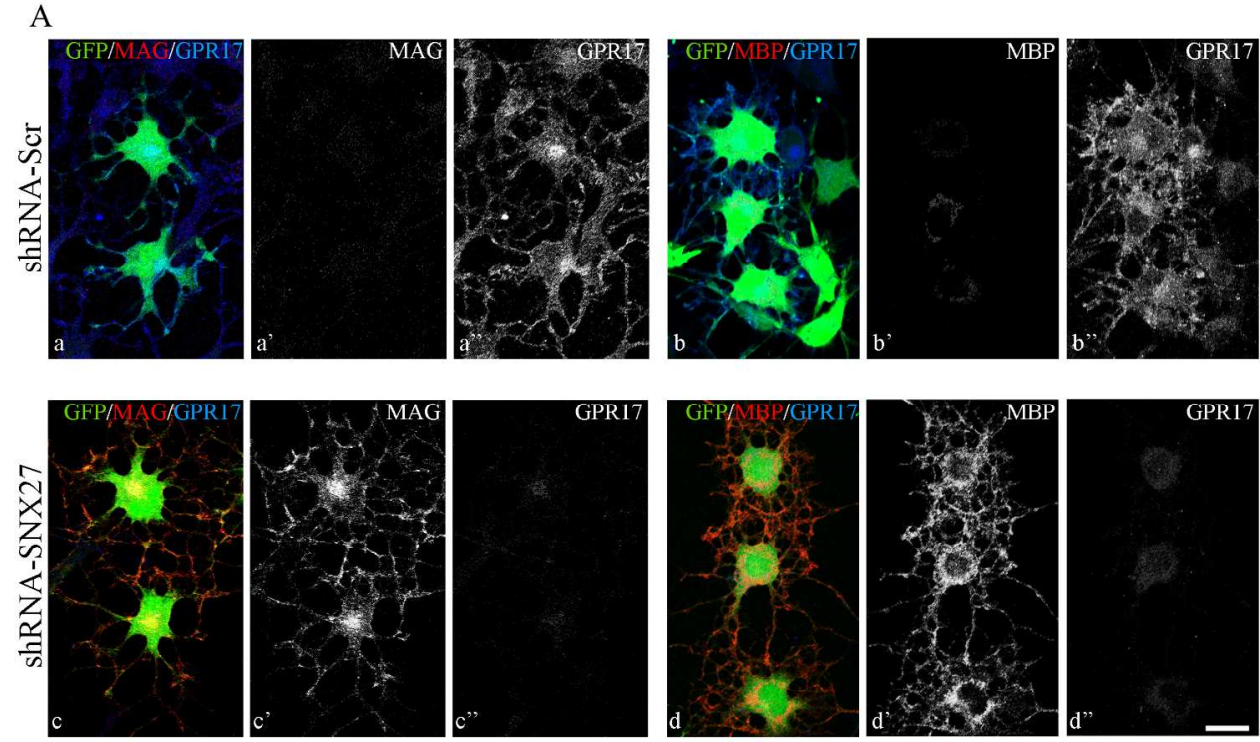

B

C
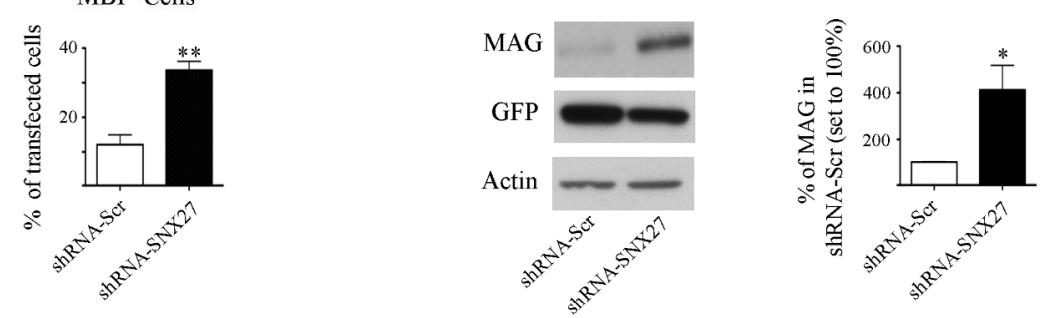

D

Primary OPC cultures

E Id 2 expression
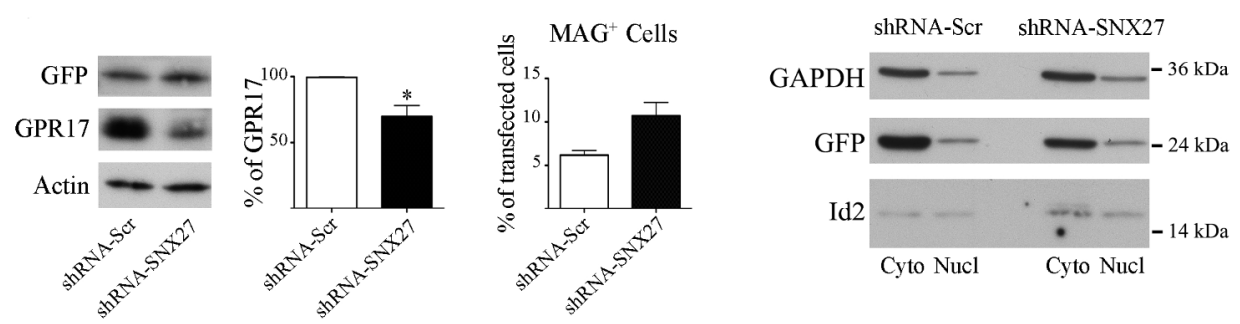

Figure 8. SNX27 knock-down accelerates OL differentiation. 
A

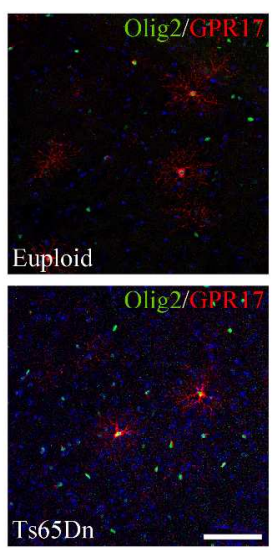

$\mathrm{C}$
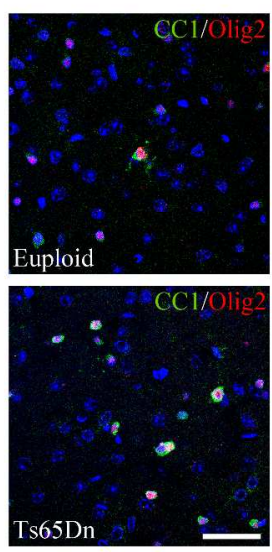

B

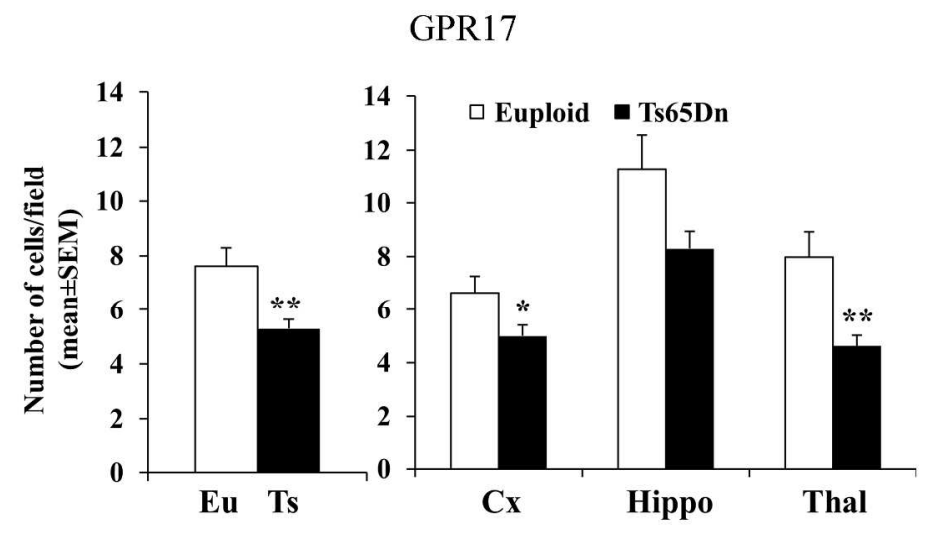

D

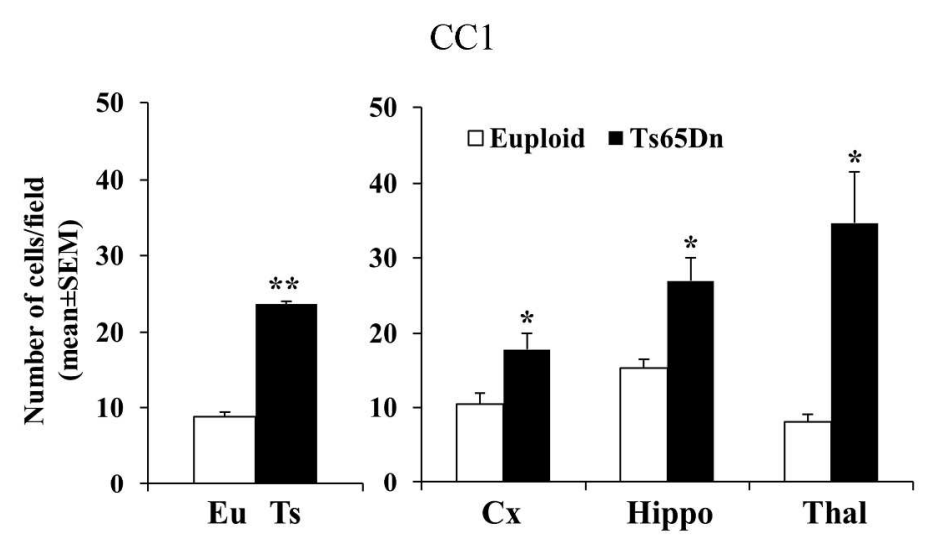

Figure 9. Reduced expression of GPR17 and increased expression of CC1, a marker of mature oligodendrocytes, in the brains of Ts65Dn mice. 
A

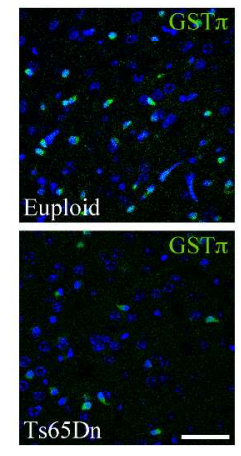

$\mathrm{B}$

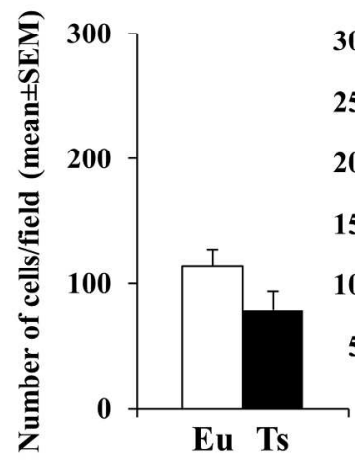

GST $\pi$

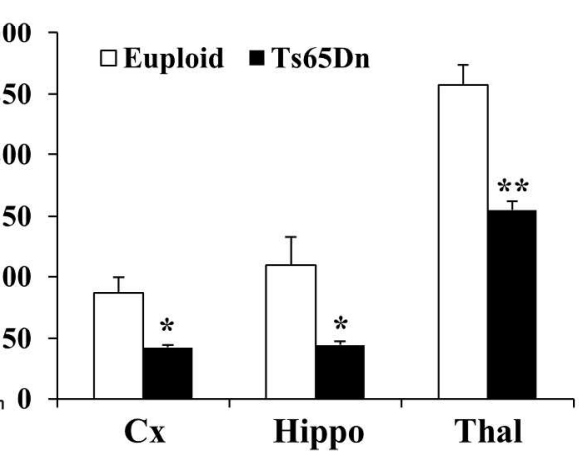

Figure 10. Decreased number of GSTn-positive cells in the brains of Ts65Dn mice. 


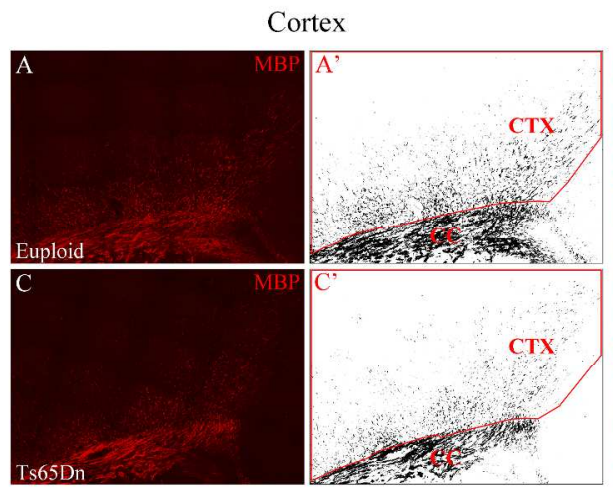

$\mathrm{E}$

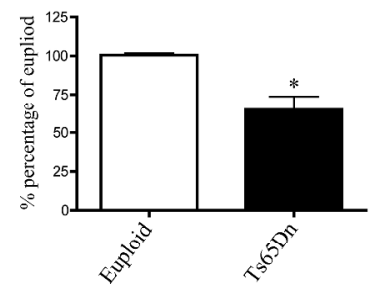

G

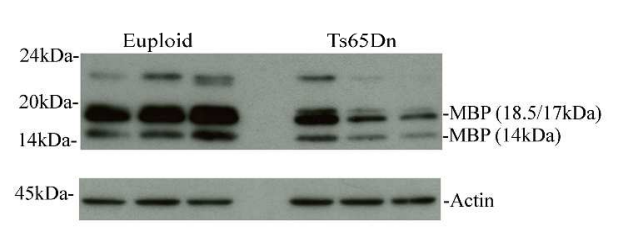

Corpus Striatum

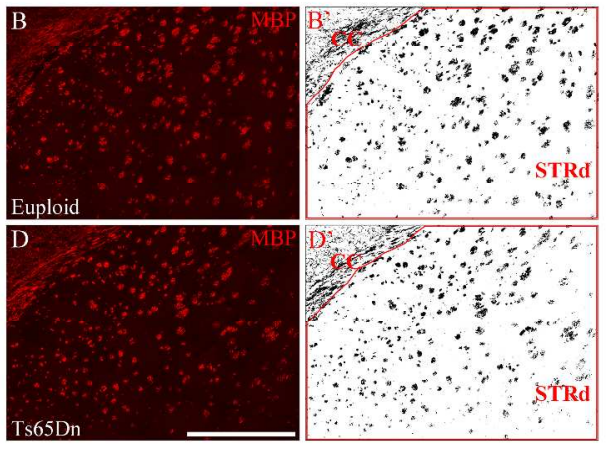

F
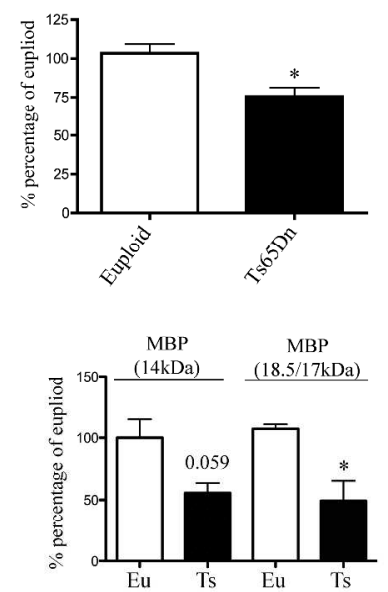

Figure 11. Decreased myelination in brains of Ts65Dn mice. 